NBER WORKING PAPER SERIES

\title{
THE AMERICAN HIGH SCHOOL GRADUATION RATE: TRENDS AND LEVELS
}

\author{
James J. Heckman \\ Paul A. LaFontaine \\ Working Paper 13670 \\ http://www.nber.org/papers/w13670
NATIONAL BUREAU OF ECONOMIC RESEARCH
1050 Massachusetts Avenue \\ Cambridge, MA 02138 \\ December 2007
}

This research uses data from Add Health, a program project designed by J. Richard Udry, Peter S. Bearman, and Kathleen Mullan Harris, and funded by a grant P01-HD31921 from the National Institute of Child Health and Human Development, with cooperative funding from 17 other agencies. Special acknowledgment is due Ronald R. Rindfuss and Barbara Entwistle for assistance in the original design. Persons interested in obtaining data from Add Health should contact Add Health, Carolina Population Center, 123 W. Franklin Street, Chapel Hill, NC 27516-2524 (addhealth@ unc.edu). This research was supported by the Committee on Economic Development PAES Project, the Pew Foundation, NIH R01-HD043411, NSF SES-024158 and the American Bar Foundation. The views expressed in this paper are those of the authors and not necessarily those of the funders listed here. We thank Amanda Edwards, Lynne Heckman, Kathryn McLellan, Derek Neal, Steve Raudenbush, and Diane Schanzenbach for helpful comments. Mary Mei, Alex Volfovsky and William Cha provided very helpful research assistance. The views expressed herein are those of the author(s) and do not necessarily reflect the views of the National Bureau of Economic Research.

(C) 2007 by James J. Heckman and Paul A. LaFontaine. All rights reserved. Short sections of text, not to exceed two paragraphs, may be quoted without explicit permission provided that full credit, including (C) notice, is given to the source. 
The American High School Graduation Rate: Trends and Levels

James J. Heckman and Paul A. LaFontaine

NBER Working Paper No. 13670

December 2007

JEL No. I21

\begin{abstract}
$\underline{\text { ABSTRACT }}$
This paper uses multiple data sources and a unified methodology to estimate the trends and levels of the U.S. high school graduation rate. Correcting for important biases that plague previous calculations, we establish that (a) the true high school graduation rate is substantially lower than the official rate issued by the National Center for Educational Statistics; (b) it has been declining over the past 40 years; (c) majority/minority graduation rate differentials are substantial and have not converged over the past 35 years; (d) the decline in high school graduation rates occurs among native populations and is not solely a consequence of increasing proportions of immigrants and minorities in American society; (e) the decline in high school graduation explains part of the recent slowdown in college attendance; and (f) the pattern of the decline of high school graduation rates by gender helps to explain the recent increase in male-female college attendance gaps.
\end{abstract}

James J. Heckman

Department of Economics

The University of Chicago

1126 E. 59th Street

Chicago, IL 60637

and NBER

jheckman@uchicago.edu

Paul A. LaFontaine

NORC

1155 E. 60th Street

Chicago IL 60637

plafonta@gmail.com 


\section{Introduction}

The high school graduation rate is a barometer of the health of American society and the skill level of its future workforce. Throughout the first half of the $20^{\text {th }}$ century, each new cohort of Americans was more likely to graduate high school than the preceding one. This upward trend in secondary education increased worker productivity and fueled American economic growth (See Goldin and Katz [2003]). In the past 25 years, rising wage differentials between high school graduates and dropouts increased the economic incentives to graduate high school. ${ }^{1}$ The real wages of high school dropouts have declined since the early 1970s while those of more skilled workers have risen sharply (See Autor, Katz, and Kearney [2005]).

According to one measure issued by the National Center for Educational Statistics (NCES), U.S. students responded to these higher incentives by completing high school at increasingly greater rates. Figure I plots the high school status completion rate overall and by race for each year since 1968 from the NCES. It is the percentage of 18- to 24-year-olds possessing a high school credential. By this measure-widely regarded as the official rate-U.S. schools now graduate nearly 88 percent of students and black graduation rates have converged to those of non-Hispanic whites over the past four decades.

The NCES also publishes a second measure of the high school graduation rate called the 17year-old graduation ratio (Figure I). This is the number of public and private high school diplomas issued by secondary schools each year divided by the size of the 17-year-old population in that year. This measure suggests a very different assessment of the U.S. secondary schooling system. ${ }^{2}$ Both the graduation ratio and status completion rate start at nearly the same level in 1968. However, contrary to the status completion rate, the graduation ratio estimates peak at 77 percent in 1969 and then slowly declined until suddenly reversing the long-time trend starting in 2002.3 
A number of recent studies question the validity of the status completion rate and attempt to develop more accurate estimators of high school graduation rates (See Greene [2001], Swanson [2004], Swanson and Chaplin [2003], Miao and Haney [2004] and Warren [2005]). Heated debates about the levels and trends in the true high school graduation rate have appeared in the popular press. ${ }^{4}$ Depending on the data sources, definitions, and methods used, the U.S. graduation rate is estimated to be anywhere from 66 to 88 percent in recent years — an astonishingly wide range for such a basic statistic. The range of estimated minority rates is even greater-from 50 to 85 percent.

This article demonstrates why such different conclusions are reached in previous studies. It uses cleaner data and better methods to estimate U.S. graduation rates. Our study is unique in its use of a wide variety of data sources and its demonstration that when comparable measures are used on comparable samples, a consensus can be reached among all data sources. After adjusting for multiple sources of bias and differences in sample construction, we establish that (1) the U.S. high school graduation rate peaked at around 80 percent in the late 1960 s and then declined by $4-5$ percentage points; (2) the actual high school graduation rate is substantially lower than the 88 percent estimate of the status completion rate issued by the NCES; (3) about 65 percent of blacks and Hispanics leave school with a high school diploma and minority graduation rates are still substantially below the rates for non-Hispanic whites. In fact, we find no evidence of convergence in minority-majority graduation rates over the past 35 years.

The decline in high school graduation is of interest in its own right as a measure of the performance of American schools. It has important implications for interpreting a wide variety of educational statistics. For example, part of the slowdown in male college attendance rates documented by Card and Lemieux (2001) is due to declining rates of high school graduation among males. In addition, half of the growing gap in female versus male college enrollments documented by Goldin, Katz and Kuziemko (2006) can be attributed to higher levels of high school graduation 
among females and larger declines in male graduation rates. Our findings also have implications for the study of the effects of educational policy changes on secondary attainment rates. Many estimates of the effects of policies on high school graduation reported in the literature are based on poorly constructed graduation estimators that produce inflated levels and inaccurate time-trends.

The rest of the paper proceeds as follows. Section II reviews the recent debate about high school graduation rates and various estimators. Section III shows how various adjustments affect the estimates. Section IV synthesizes the discussion and presents estimates of historic graduation rates by race and sex. In it, we also estimate the contribution of the decline in high school graduation rates to the recent slowdown in college attendance growth rates. Section V concludes.

\section{The Graduation Rate Debate}

For years, the NCES has published the two apparently contradictory assessments of the health of the U.S. secondary education system plotted in Figure I. Only a few scholars remarked on the discrepancy (See Finn [1987]; Cameron and Heckman [1993] and Heckman and Rubinstein [2001]). The passage of the "No Child Left Behind" Act (NCLB) in 2001 (see U.S. Congress [2001]) renewed interest among researchers in estimating high school graduation rates. NCLB made increased high school graduation a primary objective and required states and schools to monitor them as measures of adequate yearly progress (AYP). School districts and states that did not meet AYP requirements were sanctioned, primarily in the form of reduced federal funding. NCLB also revised the definition of who counts as a high school graduate. Only those students who receive a secondary credential that is fully aligned with each state's academic standards are to be counted as high school graduates. For the first time, alternative credentials, such as General Educational Development (GED) certificates and certificates of attendance, were to be explicitly excluded from state and local graduation calculations (United States Congress [2001]). ${ }^{5}$ 
Using the new definition of who is a high school graduate, many scholars claim that the United States has a dropout crisis (See Greene [2001], Swanson [2004], Swanson and Chaplin [2003], Miao and Haney [2004] and Warren [2005]). The new school of thought is that the true graduation rate is substantially lower than the rate that had been reported for years by the NCES and other governmental agencies. Contrary to the official statistics of 85-90 percent, researchers now report overall graduation rates closer to 70 percent. African-American and Hispanic rates are often calculated to be as low as 50 percent nationally (See Greene [2001] and Swanson [2004]).

Historic trends in high school graduation have also come under closer scrutiny. In agreement with the earlier findings of Cameron and Heckman (1993), some scholars find that high school graduation rates peaked in the late 1960s and have since stagnated or fallen (See Chaplin [2002] and Miao and Haney [2004]).

In response to these studies, Mishel and Roy (2006) argue that graduation rates are not nearly as low as those reported in most studies in the recent literature. They argue that overall graduation rates are 83 percent and that minority graduation rates are 75 percent, rather than the 50 percent claimed by other researchers. This paper examines these competing claims.

\section{Estimating the U.S. High School Graduation Rate}

Before turning to the data, it is important to clarify the distinction between a "completer" and a "graduate". Following the NCES convention, we use the term "high school completer" to indicate a person who either graduated high school or obtained a GED certificate. GED recipients are dropouts who are exam certified as high school equivalents through the GED testing program. High school graduates are those who receive a traditional high school diploma from an accredited high school program. 
In this section, we use household surveys, school administrative data and longitudinal surveys to recalculate national high school graduation rates by race and gender. We discuss the problems and limitations of each data source in detail and show that, after adjusting for a variety of sources of bias, all of these data sources give a consistent picture of U.S. graduation rates.

\section{A. Census and CPS-Based Estimates}

The Current Population Survey (CPS) is a monthly survey of approximately 50,000 U.S. households administered by the Bureau of Labor Statistics. It is primarily designed to track employment and earnings trends in the civilian non-institutional population. ${ }^{6}$ However, along with economic variables, the CPS also collects the educational status of each household member.

Every October, the CPS administers an educational supplement that asks more detailed questions concerning the educational history and attainment level of each household member. The NCES uses this data to calculate the 18- to 24-year-old status completion rate depicted in Figure I. Many recent papers have discussed the problems that arise from using the status completion rate as a measure of the national graduation rate (See, e.g., Chaplin [2002], Greene [2001], Swanson and Chaplin [2003] and Sum et al. [2003]). These studies claim that the status completion rate is a biased estimator of the graduation rate because: (1) GED recipients are counted as high school graduates;

(2) the institutional and military populations are excluded from the CPS; (3) one household member responds for the entire household roster (i.e. proxy response bias); (4) the CPS is not able to locate all persons eligible for the survey (i.e. low sample coverage); and (5) recent immigrants, who were never enrolled in U.S. secondary schools, are included in the estimates. The final point is irrelevant for measuring the stock of labor by skill category available to the U.S. economy. It is highly relevant for assessing the performance of American schools—-the focus of this paper. 
Using decennial Census data, we assess the importance of each of these potential biases. A sub-sample of the Census, the Integrated Public Use Microdata Series (IPUMS), contains more detailed education and demographic information than the CPS for both a 1 percent and 5 percent representative sample of the entire U.S. resident population. It is a useful tool for examining potential sources of bias in CPS-based estimates because it does not suffer from many of the disadvantages of the CPS. First, the universe is more inclusive than the CPS because it samples both the institutional and military populations. Second, coverage rates are significantly higher in the Census than in the CPS. Finally, the Census began asking immigration questions long before the CPS did so. Immigrants who did not attend U.S. schools can be identified and excluded from the calculation beginning with the 1970 IPUMS data.

The IPUMS data have two important drawbacks. In contrast to the CPS supplements that are available on an annual basis, IPUMS data are only available every ten years. In addition, the IPUMS questionnaire does not distinguish between GED recipients and regular high school graduates. However, using data from the GED testing service, we are able to estimate the total number of GED recipients in each Census for a given age range and deduct them from the total number of people reporting high school completion in the Census data. The estimate of GED recipients using this method is in very close agreement with independent estimates obtained from various data sources. ${ }^{7}$

Calculating national graduation rates by race and sex using the 5 percent IPUMS for the year 2000, we find that the status completion rate measure from the CPS suffers from significant bias. ${ }^{8}$ The two largest sources of bias are GED certification and response bias to the CPS education question. Low sample coverage is empirically unimportant. Bias from the CPS exclusion of military personnel is negligible. The exclusion of prisoners plays only a small role overall, but is important 
when computing race and gender differentials in graduation. We now discuss each of these points in detail and compute their effect on graduation rate estimates. ${ }^{9}$

\section{The GED}

The GED began as a small-scale program designed to certify veterans who interrupted their high school training to serve in the armed forces during World War II. Quinn (2008) documents how the GED changed its original mission of certifying veterans to become a substitute for high school graduation among school-age youth. In 2001, more than 1 million high school dropouts attempted to certify as "high school equivalents." Of these, 65 percent were under the age of twenty-four. ${ }^{10} \mathrm{In}$ 1960, only 2 percent of all new high school credentials were awarded through equivalency exams in the United States. By 2001, nearly 20 percent of all new high school credentials were achieved through GED certification. ${ }^{11}$

The GED is generally accepted as the equivalent of a high school diploma for college admissions and for determining eligibility for job training and financial aid programs. Historically, GED recipients have also been counted as high school graduates in many official federal, state, and local education statistics.

Cameron and Heckman (1993) and Heckman and LaFontaine (2006, 2008) show that a GED is not equivalent to a high school diploma. Although GED recipients have the same measured academic ability as high school graduates who do not attend college, they have the economic and social outcomes of otherwise similar dropouts without certification. Despite measures of cognitive ability similar to high school graduates, GED recipients perform significantly worse in all dimensions when compared to them (Heckman and Rubinstein [2001]). GED recipients lack noncognitive skills such as perseverance and motivation that are essential to success in school and in life. The GED opens education and training opportunities but GED recipients do not reap the potential 
benefits because they are unable to finish these activities. GED recipients attrite from the military at the same rate as other dropouts and they exit post-secondary schooling with nearly the same degree attainment rates as other dropouts who start with no credential (See Laurence [2008] and Heckman and LaFontaine [2008]).

Despite overwhelming evidence to the contrary, the GED is often still equated with a high school diploma and the line between the two credentials is being increasingly blurred. Many states use the GED program to issue state-accredited high school diplomas on the basis of GED test scores. In New Jersey, for example, an individual need only mail in GED test scores that meet the state's GED score requirement and qualify for a state-endorsed high school diploma. Candidates do not even need to reside in the state in order to qualify.12 These credentials are then included in official state diploma counts issued by NCES and in calculations of state graduation rates. ${ }^{13}$ In fact, in many years, diplomas issued are greater than the number enrolled in $12^{\text {th }}$ grade. Unsurprisingly, New Jersey is estimated to have one of the highest graduation rates in the country (See Greene [2001] and Swanson [2004]). ${ }^{14}$

Another troubling aspect of the GED program is its disproportionate use by minorities. The GED program conceals serious problems in minority education. ${ }^{15}$ Historic trends in conventional status completion rates suggest that minorities are closing the secondary schooling gap with the majority (Figure I). However, minority male high school completers are almost twice as likely as white males to possess a GED certificate (Cameron and Heckman [1993]). A substantial proportion of the black-white difference in GED attainment rates is due to the large number of minority GED credentials being produced by the prison system (See Gensowski [2008]). Prison GED recipients now account for over 10\% of all GED certificates issued in the U.S. each year. ${ }^{16}$ If those who have served in prison are removed from the calculation, the GED attainment rates for minority and majority group males are similar. Not only is most of the convergence in male minority 
high school completion rates to those of whites due to higher GED certification rates among minorities, but a substantial portion of these credentials is produced in the prison system.

The 2000 IPUMS data can be used to calculate the graduation rate for 20-24 year olds both including and excluding GED recipients. Counting GED recipients as dropouts has a substantial impact on overall graduation rates (Figure II). ${ }^{17}$ The estimated graduation rate is biased upward by 7.7 percentage points when GED recipients are counted as high school graduates. The bias is larger for males than females due to high rate of GED certification in prisons among males (Figures III and IV). Excluding GED recipients lowers minority graduation rates more than majority rates. The

overall black rate falls by nearly 2 percentage points more than the overall white rate after excluding GED recipients (Figure II). ${ }^{18}$ Largely due to the disproportionate number of black males obtaining GED credentials in prison, the most significant bias occurs in the black male estimates-nearly 11 points (Figure III).

\section{Incarceration}

There has been an explosion in the growth of the incarcerated population since the early 1980s..$^{19}$ In 2002, the total incarcerated population exceeded 2 million people for the first time. ${ }^{20}$ Minority males, especially young black males, have been disproportionately affected by tougher anticrime measures. Nearly one out of every ten black males age 18-24 is now incarcerated and it is estimated that more than one-third of all black male high school dropouts age 20-35 were in prison on an average day in the late 1990s - a higher proportion than found in paid employment (Western and Pettit [2000]).

There is a strong negative causal relationship between education and crime (Lochner and Moretti [2004]). Thus, the educational attainment levels of prisoners are low.21 Among the prison 
population, 78 percent are uncertified high school dropouts or GED recipients. Furthermore, 56\% of the incarcerated high school completion category comes via GED certification.

Excluding the prison population has only a small effect on the overall graduation rate, increasing it by slightly more than 1 percent (Figure II), but has more significant impacts on race and gender comparisons. ${ }^{22}$ Overall male rates are biased upward by 2.1 points when excluding prisoners while overall female rates are nearly unchanged (Compare Figures III and IV). Excluding the prison population decreases the estimated black-white gap in high school graduation rates by 2.6 percentage points. This change is even greater when the sample is limited to males. The black-white male gap is biased downward by nearly 5 points when the prison population is excluded, as it is in computing status completion rates based on CPS data.

\section{Armed Forces}

In 2000, 91 percent of military recruits across all services were high school graduates; 7.4 percent were GED recipients, and only 1.5 percent uncertified dropouts. ${ }^{23}$ Most military personnel are high school graduates and excluding them could potentially bias the estimated high school graduation rate downward. ${ }^{24}$ However, because the military is a relatively small segment of the population, the exclusion of the military population from the CPS has insignificant effects on the overall graduation rate. The net effect of excluding the armed forces is one-tenth of a percentage point overall (Figure II). The estimates by race are also largely unchanged due to similar high school attainment rates among enlisted whites and minorities.

\section{Immigration}

Many CPS-sampled 18-to-24-year-olds are recent immigrants who never attended high school in the United States. Hispanics account for most of this group. The Census data show that almost half of 
Hispanics in this age group immigrated within the last ten years. These recent Hispanic immigrants are primarily low-skilled Mexican workers who have significantly lower high school attainment rates than U.S.-educated Hispanics. The large influx of immigrants into the United States in the past two decades imparts a serious bias to the estimates-both in levels and in trends. ${ }^{25}$ A meaningful evaluation of the performance of the U.S. educational system should not include people who never attended U.S. schools or those who did so only briefly.

To examine the effect of immigration on the estimates, we exclude immigrants who entered the U.S. within the past 10 years in our 20-24 year old sample. Including immigrants biases the overall high school graduation rate downward by 2.6 points (Figure II). The largest bias is observed for Hispanic attainment rates_nearly 11 percentage points overall. Hispanic male rates are more strongly affected than female rates by the inclusion of immigrants (Figures III and IV). We show in the next section that the trends in Hispanic graduation rates are also strongly affected by this bias since the migration of workers with low levels of education has increased substantially over the past 40 years.

\section{Low Coverage and Response Bias}

Low coverage rates are a potential source of bias in CPS data. This source of bias is distinct from the CPS exclusion of the non-civilian and institutional populations. Coverage is usually discussed in terms of the coverage ratio, defined as the estimated population for a given group divided by the known target population size for that group based on an independent data source (e.g. Census). The coverage ratio of the CPS survey instrument is .92 overall, indicating that the CPS population estimate for the civilian non-institutional is $92 \%$ that of the Census estimate. However, coverage rates vary substantially by age and race. ${ }^{26}$ Young minority males are the least likely to be sampled. For example, the coverage ratio for black males ages 20-29 is only .66 in the CPS. In contrast, the 
coverage ratio for non-black males in this age group is .85. The final CPS sample weights are adjusted by race and sex to account for this known undercoverage in an attempt to eliminate potential bias. ${ }^{27}$ However, Sum et al. (2003) argue that low coverage leads to an upward bias in graduation rates, because those who are missed by the survey likely have lower educational attainments than the sampled population and only adjusting the weights will not fully correct for this.

The Census data allow us to partially assess the role of incomplete coverage in estimating graduation rates since Census coverage is much higher than CPS coverage. A concerted effort is made by the Census Bureau to obtain accurate counts of the entire resident population every ten years including the military and institutional populations. As a result, the overall Census coverage ratio is .98 (See Web Appendix Figure S.7). ${ }^{28}$ Minority coverage also far exceeds that of CPS data. The coverage ratio for black males and females age 20-29 in the Census is .91 and .96, respectively. In addition, the inclusion of the incarcerated and military personnel in the Census data further mitigates the potential bias of CPS-based estimates.

To assess the role of undercoverage in biasing CPS estimates, we compare the educational attainment distributions in the CPS March 2000 demographic supplement for the civilian noninstitutional population with those found in the 2000 IPUMS data. ${ }^{29}$ The CPS March and IPUMS educational attainment question are essentially the same. Due to the similarity in sample design and timeframe, the estimated population counts by educational category should be closely aligned. ${ }^{30}$

The overall population totals for 20-24 year olds in the civilian non-institutional population are nearly identical in the two data sources, but the educational attainment distributions differ considerably (Figure V). The CPS overestimates the fraction of high school completers (both GEDs and high school graduates) in the 20 - to 24 -year-old population relative to the IPUMS and undercounts uncertified dropouts. As a result, the overall graduation rate based on the CPS data is 
nearly 2 percentage points higher than a Census-based estimate for this age group. The bias is even greater for minority groups. The difference in the percentage of the Hispanic population that report being a dropout is nearly 3\% points lower in the CPS March sample relative to Census (Figure V).

From this evidence it would appear that the low sample coverage in the CPS survey is a plausible explanation for the discrepancy in the dropout estimates. As predicted, the CPS underestimates those with low educational attainments and more so for minority groups.

A closer examination of the distributions of educational responses in the two data sources reveals that this explanation is unlikely. The CPS and Census closely align across all educational categories with the exception of two. ${ }^{31}$ The CPS undercounts dropouts who completed $12^{\text {th }}$ grade, but received no diploma and overestimates the percentage of high school graduates who did not attend college relative to the Census (Figure V). The difference between the two data sources in the number of dropouts reporting all other grade levels (completing $11^{\text {th }}$ grade or less) is negligible. In fact, if we equate the percentage of the population in the CPS " $12^{\text {th }}$ grade, no diploma", category to that found in the Census, the estimated total number of high school completers and dropouts are nearly equal for all race and sex groups in the two datasets (See the high school counterfactual in Figure V). ${ }^{32}$ The discrepancy in the $12^{\text {th }}$ grade, no diploma category accounts for nearly all the difference in the estimated graduation rate in the two data sources.

Given that the CPS survey underestimates the number of dropouts in only one category, it is unlikely that low sample coverage is the source of the discrepancy. If undercoverage is the source of bias, then we would expect a more uniform pattern of undercounting across all of the lower education categories.

Scanniello (2007) reports a similar discrepancy when comparing educational responses in the CPS March against the American Community Survey (ACS). The ACS is a new Census bureau survey similar in sample design, mode of administration, and coverage to the IPUMS data. 
Scanniello suggests that the discrepancy in the $12^{\text {th }}$ grade, no diploma category likely results from differences in survey administration. The ACS and Census surveys are primarily administered through a mail questionnaire while the CPS is primarily conducted through telephone interviews. It appears that respondents are able to more accurately distinguish between the two categories in the IPUMS and ACS data for two reasons. First, respondents see the available choices when responding to the paper-based ACS and IPUMS survey whereas the choices are read to them over the phone in the CPS. This may be particularly important for getting respondents to distinguish between completing $12^{\text {th }}$ grade with no degree and finishing with a diploma. Second, the ACS and Census instrument allows each member of the household to fill out questions that pertain to them rather than have one person respond for the entire household as is the case in the CPS. CPS proxy respondents are unlikely to be able to distinguish between someone who completed $12^{\text {th }}$ grade with or without a diploma. ${ }^{33}$

The final two columns of Figure V show the total bias in the CPS survey design and the total bias in the CPS status completion rate by race. The undercounting of dropouts and the exclusion of the prison and military samples in the CPS results in a net bias of 3 points overall and over 5 points for blacks. The total bias in the 2000 status completion rate computed using CPS data is $8 \%$ overall and over 15 points for blacks. The bias in the status completion rate as an estimate of the Hispanic high school graduation rate in 2000 is very small due to the large number of recent immigrants that tend to offset the other sources of bias. ${ }^{34}$

\section{B. Common Core of Data Based Estimates}

The Common Core of Data (CCD) is collected from state departments of education and contains the number of students enrolled in each grade level in a given year, as well as the number of high school diplomas issued in that year. From these annual counts, an approximate cohort high 
school graduation rate can be calculated by dividing the number of diplomas issued in a given year by the number of entering ninth-grade grade students four years earlier. Some measures adjust for migration between states in the enrollment and diploma counts while others average one or more years of enrollment data to form a smoothed estimate of the entering freshman class. Recent graduation rate estimates based on these estimators are between 68-70 percent - significantly lower than those calculated using household survey data (See Greene [2001] and Swanson and Chaplin [2003]).

As noted by Mishel and Roy (2006), the primary reason that most of the proposed administrative-data-based graduation estimators produce lower estimates than those from other data sources is because they condition on $9^{\text {th }}$ grade enrollments. ${ }^{35}$ The data do not give the number of entering ninth graders, but instead provide the total ninth-grade enrollment in each year. The $9^{\text {th }}$ grade is the most common grade for upper level students to be held back. This causes CCD estimators that use $9^{\text {th }}$ grade enrollments to be biased downwards because they double count retained students in the denominator.

To gauge the magnitude of this bias, we estimate grade retention by calculating the percentage change in $8^{\text {th }}$ grade public school enrollment counts in a given year to the next year's $9^{\text {th }}$ grade enrollment counts (Figure VI). In the mid-1950s, fall ninth-grade enrollment counts were nearly identical to the previous year's fall eighth-grade class size. By 2000, they were over 13 percent larger. Ninth-grade retention bias is even greater for minorities than for whites. Minority $9^{\text {th }}$ grade enrollments are often 20-26 percent greater than the previous year's $8^{\text {th }}$ enrollment count, as opposed to only 6-10 percent for whites. This severely biases estimated minority graduation rates downward relative to those of whites if conditioning on $9^{\text {th }}$ grade enrollment counts. The claim that only 50 percent of minorities graduate high school is due to high rates of $9^{\text {th }}$ grade retention and estimators that do not correct for this source of bias. ${ }^{36}$ 
To avoid this problem, we use the previous year's eighth-grade enrollments to proxy for the entering ninth-grade class. This estimator-also used by Miao and Haney (2004)—avoids the problem of ninth-grade retentions and produces estimates that are consistent with Census and all other data sources. Figure VII plots the estimated trends in public school graduation from the $8^{\text {th }}$ grade estimator for the graduating classes of 1960-2005. We also indicate the sampling period of the major longitudinal data sources that we use as well as the occurrence of two major educational policy changes for reference. Overall, the U.S. graduation rate steadily increased throughout the early 1960s and peaked in the early 70s. It then steadily declined from this point until the publication of $A$ Nation at Risk (See U.S. National Commission on Excellence in Education [1983]). A decline again followed until 2002, when NCLB graduation rate monitoring was implemented. Even with this recent surge, the U.S. graduation rate has never fully recovered to its early levels.

NCLB gives schools strong incentives to raise graduation rates by any means possible. When monitoring was implemented in 2002, minority retention dropped sharply and graduation rates turned upward, especially for minority groups (Figure VI and VII). ${ }^{37}$ A similar pattern is observed following the publication of $A$ Nation at Risk. Whether these represent real gains or are an indication of schools cheating the system in the face of political pressure remains an open question for future research, although the timing suggests strategic behavior.

Comparisons between the CCD and Census-based estimates are in close agreement. Assuming that students graduate at age 18, comparing the CCD estimates for the graduating classes of 1994-1998 to the 2000 Census estimates for those ages 20- to 24 , we find that the two data sources agree. The overall Census estimate for these graduating cohorts is 77.1 percent while the CCD estimate is 76.6 percent. The predicted rates for whites, blacks and Hispanics in the Census are 81 percent, 66 percent, and 63 percent, respectively. Using CCD data, we estimate rates of 80.5 percent, 62 percent, and 65 percent, respectively. 38 
Widely-used estimators that condition on $9^{\text {th }}$ enrollment greatly underestimate graduation rates, especially for minorities (Figure VIII). In 1960, the bias associated with conditioning on $9^{\text {th }}$ grade enrollment size rather than $8^{\text {th }}$ grade enrollment was nearly zero. In recent years, the difference between the two estimators is as large as 9 points overall and 14 points for minorities. For the same 2000 Census cohort previously discussed, the $9^{\text {th }}$ grade estimator predicts an overall graduation rate of only 68 percent. This is very different from the Census estimate of 77 percent. Furthermore, estimated minority graduation rates miss the mark completely. The estimated Hispanic rate is only 52 percent, while the black rate is an even lower 50 percent. Both estimates differ substantially from those obtained from both the Census and the $8^{\text {th }}$ grade estimator.

While the Census and $8^{\text {th }}$ grade estimator generally agree in levels and exhibit the same overall trends in graduation over time, we will show that the $8^{\text {th }}$ grade CCD estimator consistently produces slightly lower overall estimates $(\sim 1 \%)$ than the Census and longitudinal data sources over time. For minorities, the disparity between the two sources is greater, generally 3 to 5 points. The discrepancy results primarily from a difference in what is being estimated. Many post-high school training and education programs such as Job Corps, Adult Basic Education and Adult Secondary Education also issue state-endorsed regular high school diplomas that are not counted in the CCDschool-based data. The number of diplomas issued by these programs is relatively small overall since GED certification is the primary focus. ${ }^{39}$ However, these post-schooling diplomas have a greater impact on estimated minority rates since enrollment in these programs draws heavily from minority populations. CCD-based measures provide the best indicator of the performance of American public schools while the Census and other survey data are more indicative of final attainment. 


\section{Historic Trends and Comparisons across Data Sources}

This section presents estimates of high school graduation rates for all race and sex groups over time using a wide range of data sources. The major conclusion we reach from this analysis is that graduation rates fell by 4-5 percentage points over most of the past 40 years. The decline was concentrated among males, and racial gaps have largely remained unchanged.

\section{A. Census}

Combining Census data with a number of different independent data sources, it is possible to construct accurate high school attainment measures by race and sex in each available Census sample. We use these outside data sources to estimate the race and gender distributions of all GED recipients ages 20-24 and 25-29 in each Census from 1970 through 2000.40 This allows us to compute graduation rate estimates by race and sex for two cohorts that, together, span the entire 10 years between each of the available decennial Census samples.

Figure IX plots the estimated Census graduation rates by cohort and race. These rates exclude recent immigrants and do not count GED recipients as high school graduates. The highest estimated graduation rates are for the first two cohorts, at nearly $81 \%$. For later cohorts, the graduation rate declines to $77 \%$ in the most recent Census. The Census estimates are in near perfect agreement both in levels and trends with those estimated from CCD data using the $8^{\text {th }}$ grade estimator shown in Figure VII.

Gaps by race have also remained nearly unchanged for cohorts born after 1951-1955 (i.e. unchanged for cohorts of 25-29 year olds in the 1980 and later Censuses). The estimated gap between blacks and whites is $15 \%$ for this cohort and nearly identical for $20-24$ year olds in the 2000 Census. The corresponding gaps between whites and Hispanics (excluding immigrants) are 20\% and $19 \%$ for these two cohorts, respectively. We also estimate the bias due to including recent 
immigrants in the Hispanic calculations by computing Census rates that include these individuals. The bias that results from including recent immigrants has grown from 2 percentage points in the first cohort to nearly 9 points for the latest cohort.

Calculations by gender reveal that the decline in high school graduation is almost exclusively concentrated among young males (Figures X and XI). The overall male graduation rate fell 7 percentage points from the first to the last cohort, while the female rate fell by only 1 point. The forces affecting the increasing high school dropout rate operate more strongly on men than on women.

\section{B. Longitudinal Data}

This section uses a variety of longitudinal surveys that confirm the conclusions from the estimates based on CPS and Census data. An advantage of the longitudinal data in sources we use is that educational attainment questions are asked and verified each year. In addition, in many longitudinal surveys that we examine the educational responses of the individual were verified through official high school transcripts. Thus, a more detailed and accurate educational history for each individual can be formed. One major disadvantage of longitudinal data sources is potential bias due to sample attrition. As members of the sample leave the survey for various reasons (e.g. death, survey refusal, survey design), the remaining sample may no longer be representative of the underlying population.

\section{a. NLS Estimates}

The National Longitudinal Surveys (NLS) have collected detailed schooling, employment, labor market and social measures on multiple cohorts of young adults over the past 40 years. This section uses the NLS66 Young Men and NLS68 Young Women cohorts (born 1946-1950), two cohorts of NLSY79 data (born 1957-1960 and 1961-1964), and the most recent NLSY97 cohorts (born 1980-1984), to examine graduation time-trends in longitudinal data. ${ }^{41}$ For the two NLSY79 
cohorts and the one from NLSY97, high school transcripts were collected for a large number of the sample members. This allows us to verify educational responses against official school records. In the small number of cases where there was a discrepancy between reported education and the official school transcript, the transcript report was used. See the Web Appendix (http://jenni.uchicago.edu/estimating hsgraduation) for further details regarding NLS sample construction.

Examining graduation rate estimates across four of the National Longitudinal Surveys (NLS) confirms the overall conclusions of the Census analysis. The highest estimates are for the NLS young men and women who were born between 1946 and 1950 (Table I). The graduation rate then declines slightly in the first NLSY79 cohort (those born 1957-1960) until falling off for those born after 1960. This is very similar to the observed Census patterns shown in Figure IX. By the last NLS cohort, the NLSY97 sample (those born 1980-1984), the overall graduation rate has fallen nearly 4 points relative to the early NLS cohort. An additional longitudinal dataset, the National Longitudinal Study of Adolescent Health (Add Health) survey, confirms the lower estimates found in the NLSY97 sample. Add Health respondents were born during the same period as the NLSY97 sample and the estimated graduation rate is nearly identical for all race and sex groups in the two surveys.

Estimates by race and sex are also in agreement with Census estimates and confirm the low graduation rates for minority students found in Census and CCD data. The NLS male graduation rate declines sharply while the female rate remains relatively stagnant. As is observed in Census data, the black rate rises from the earliest NLS68 cohorts and then remains stagnant for both NLSY79 cohorts through the NLSY97 cohorts. The NLSY79 estimates a high school graduation rate for blacks born from 1957-1960 of 69.7\%. The estimate for blacks born 25 years later is even slightly 
lower at $69.1 \%$. The levels in black graduation rates by cohort are also entirely consistent with those found in Census data.

\section{b. $\quad$ HSB and NELS Estimates}

The two exceptions to the overall trends across the longitudinal data sources are the two NCES surveys; the High School and Beyond Sophomore Cohort (HSB) and the National Educational Longitudinal Survey (NELS).42 The overall estimates from these data sources are significantly higher than those found in NLS and Census data and also exhibit anomalous patterns by race and sex. For instance, the black male graduation rate estimates in NELS are above those of black females. This is not observed in any other data source.

Mishel and Roy (2006) claim that these data are the best available for calculating graduation rates since the educational attainments of sample members are verified using school transcript records. However, they do not account for a number of problems with the data that tend to impart an upward bias to the estimates. After correcting for these biases, we find that both NELS and HSB data are consistent with the overall estimates in other data sources for the given cohorts.

The HSB base year survey was administered to sophomores enrolled in the spring of 1980 while the NELS base year sample is composed of $8^{\text {th }}$ graders in the spring of 1988 . Both the HSB and NELS surveys were designed to be nationally representative of U.S. students enrolled in public and private schools in the respective grades. However, both surveys excluded students from the initial samples who were identified by school administrators as having either limited English proficiency or learning/physical disabilities. The excluded students are called base-year-ineligibles and compose approximately $5 \%$ of the NELS base year $8^{\text {th }}$ grade sample. These base-year-ineligible students were primarily minority males and were excluded because it was thought that the NELS testing battery and questionnaire would be too stressful for them. ${ }^{43}$ It is unknown exactly how many 
$10^{\text {th }}$ graders were excluded from the HSB sample but we estimate based on enrollment counts that it is close to $4 \%$ of the sample and similar in race and gender composition to the NELS ineligibles.

The NCES sub-sampled and resurveyed the original NELS cohort in 1990, 1992, 1994, and 2000. These survey years correspond to sophomore year, senior year, two years after expected graduation and eight years after expected graduation, respectively. The sample was also "freshened" in 1990 and 1992 to ensure a representative sample of both $10^{\text {th }}$ and $12^{\text {th }}$ graders. The freshened sample is composed of students who were not enrolled in $8^{\text {th }}$ grade in the spring of 1988 but who were enrolled in an eligible school in either $10^{\text {th }}$ or $12^{\text {th }}$ grade in 1990 and 1992 . These students are a heterogeneous group that includes those who skip or repeat a grade and recent immigrants among others.

The original HSB sophomore cohort of 1980 was also sub-sampled and resurveyed in 1982, 1984, 1986 and 1992. These survey years correspond to senior year, two years after expected graduation, four years after expected graduation and ten years after expected graduation. The HSB sample was not freshened.

The NELS and HSB sample designs are complex and results derived from them are strongly affected by the choice of weights due to a series of non-random sampling procedures employed by NCES in both surveys. The results reported by Mishel and Roy (2006) for the NELS use weights that exclude the base-year-ineligible sample. ${ }^{44}$ This results in an upward bias in the estimated NELS graduation rate. A further problem is that they estimate the graduation rate using the fourth followup. In the fourth follow up, the target population changed from the previous samples. For the first time, those who were incarcerated or institutionalized at the time of survey were excluded (See Curtin, et al. [2002]). As previously demonstrated for the CPS and Census estimates, such exclusions impart an upward bias to estimated graduation rates, especially for black males. The base year $10^{\text {th }}$ 
grade sampling frame of the HSB survey adds a further complication to estimating national high school graduation rates because those who drop out prior to $10^{\text {th }}$ grade are never sampled.

We account for these multiple sources of bias in the following manner. First, we use the NELS third follow-up administered in 1994. By this year, respondents were around age 20 and nearly the entire sample had completed secondary schooling. Only .35\% of the sample is still enrolled in high school at the survey date, and only 117 total cases out of over 12,000 report having attained a high school diploma after the third follow up. Second, we use NLSY79 and Census data to estimate the number of students by race and sex who dropped out prior to $10^{\text {th }}$ grade in the HSB sample. These dropouts are then included in the final graduation rate estimates. Finally, we estimate the high school graduation rate for the base year ineligible samples in HSB and NELS and include them in the final estimates. 45

Table II shows the close agreement across all the data sources we have examined to both each other and the HSB survey. The $10^{\text {th }}$ grade enrollment estimates in CPS October, Census, CCD and NLSY79 are nearly identical. The HSB survey undercounts $10^{\text {th }}$ grade enrollments, primarily in public schools, due to the exclusion of the base year ineligible sample. We estimate the base year ineligibles as the difference in the total HSB and Census enrollment counts as $3.45 \%$ of the original $10^{\text {th }}$ grade cohort. The base year exclusion rate for blacks is over $10 \%$. The high school diplomas issued in 1982 totals are also nearly identical in NLS, CCD and HSB data. While the CPS October survey correctly estimates enrollment counts, it consistently underestimates diploma counts at older ages. These patterns hold across all race groups.

At the bottom of Table II, we compute three high school graduation rate estimates in the HSB data. The cohort rate is the percentage of the base year eligible HSB cohort and pre- $10^{\text {th }}$ grade dropouts that attain a high school diploma by the final survey round in 1992. The on-time cohort rate is the percentage of the base year eligible cohort that graduates by 1982 (the expected year of 
graduation for this cohort). The final cohort rate adjusts the initial cohort rate for the base year ineligible sample. Excluding base year ineligibles raises the graduation rate by about one percentage point overall but raises that black rate by over 4 points. The final estimated graduation rates across all data sources are similar for all groups and are within survey sampling error of each other.

Using the third follow up to estimate NELS graduation rates, and including the ineligibles, again yields very similar estimates to graduation rates based on other data sources (See Table III). The estimated numbers of diplomas issued in 1992 as well as $8^{\text {th }}$ grade enrollment counts are nearly identical in the CCD and NELS after adding back the ineligible sample to NELS. The one exception is for black enrollment counts where NELS consistently underestimates totals relative to Census and CPS data. The CPS again estimates fewer diplomas issued than the other data sources.

From the NELS sample, we can construct both a final longitudinal cohort rate and an $8^{\text {th }}$ grade estimator comparable to that employed in the CCD. The NELS and CCD $8^{\text {th }}$ grade estimator, diplomas issued in 1992 divided by $8^{\text {th }}$ grade enrollments in 1988, yield nearly identical graduation rates for this cohort while the overall final cohort rate estimate is only 0.2 percentage points higher. The CCD estimator by race consistently produces lower estimates than either Census or NELS data but the CCD estimates only capture degree completion through schools and not those obtained in post-schooling educational programs. The CCD data actually estimate a greater number of high school diplomas issued to blacks in 1992 than do the NELS data, but the NELS cohort graduation rate is higher due to the low $8^{\text {th }}$ grade enrollment estimates for blacks.

NCLB requires that states estimate on-time graduation rates like the ones we calculate here in the NELS and HSB data. Some claim incorrectly that the CCD provides a measure of on-time completion. The CCD $8^{\text {th }}$ (or $\left.9^{\text {th }}\right)$ grade estimator is a smoothed measure of high school graduation across multiple cohorts since retained students will be included in subsequent high school diploma totals. The difference in the 8th grade estimator and the estimated cohort rate is a function of cohort 
sizes, retention rates, change in graduation rates between cohorts and early graduation, among other factors. The similarity in the $8^{\text {th }}$ grade estimator and NELS cohort rate show that these factors play only a small role overall but may be more important in explaining discrepancies in minority estimates for whom grade retention is high. If the CCD and Census based measures were on-time rates, they would be significantly lower, as is confirmed in the NELS and HSB data. The on-time-graduation rates are about $4 \%$ lower overall, and the difference is even greater among minorities.

One final point is that the NELS sampled a peak cohort for U.S. graduation. Both the CCD and Census estimates confirm that the graduating class of 1992 (those born around 1974) attained unusually high levels of U.S. graduation for recent years. They are not representative of the decline that followed (See Figure VII).

Our analysis of the longitudinal data confirms two important facts about high school attainment rates. First, the overall graduation rate has fallen in the past 35 years. Children born in the late 1940s graduated at a higher overall rate than do today's children. The overall rate in the NLS young men and women cohorts was nearly 82 percent, whereas the overall rate in NLSY97 was 77.5 percent. This is again consistent with Census data in both trends and levels. Second, minority graduation rates have shown little improvement on the rates attained by the early 1950s birth cohorts. In addition, this section shows that all of the major longitudinal data sources are entirely consistent with estimates obtained from both Census survey data and CCD school administrative data.

\section{Comparisons Across Data Sources}

Recent graduation rate analyses report widely different and often contradictory estimates. However, when similar methods are used on the same populations, estimated graduation rates largely agree in both trends and levels for all race and sex groups. We summarize our discussion by comparing the 
estimates obtained from the Census household data (correcting for GED recipients and recent immigration) with those obtained from longitudinal data sources such as the NLSY surveys, as well as the estimates obtained from NCES and CCD data. In addition to the data sources discussed so far, we add the National Survey of Families and Households (NSFH). ${ }^{46}$ Figure XII makes the comparison across birth year cohorts and data sources. Comparisons of the same cohorts, using the same definition of high school graduation, lead to agreement in the estimates across all data sources in both overall levels and trends.

\section{Decomposition of Historic Trends}

When accurately measured, the U.S. high school graduation rate has declined at a time when the returns to completing high school have greatly increased. The slowdown in the high school graduation rate accounts for a substantial portion of the recent slowdown in the growth of college educated workers in the U.S. workforce. This slowdown is not due to a decline in rates of college attendance among those who graduate high school (Table IV and Figures XIII-XV). ${ }^{47}$ Table IV, panel A presents the change in the probability of high school graduation, overall and by gender, over the past century. It shows that the growth in college attendance and graduation for cohorts born before 1950 was fueled by growth in high school graduation. This contribution diminishes and turns negative in more recent cohorts.

The bottom two panels of Table IV perform standard growth accounting, decomposing the change in attendance (and graduation) into the change due to high school graduation and the change in college attendance given high school graduation. In them, we also examine college graduation given college attendance. The decline in high school graduation is greater for males than it is for females, accounting in part for the differential growth in college attendance for women that is discussed in Goldin, Katz and Kuziemko (2006). As a result of this decline, men now graduate from 
high school at significantly lower levels than women (Compare Figures XIV and XV). For recent birth cohorts, the gap in college attendance between males and females is roughly $10 \%$. However, the gap in college attendance given high school is only 5\%. Approximately half of the growing gender gap in college going and a large part of the sluggishness in the growth of college educated labor during a time of rising economic returns to skilled labor can be explained by declining rates of high school graduation.

\section{Conclusion}

This paper extensively documents that the U.S. high school graduation rate is neither as low as some alarmists claim, nor as high as many believe. Calculating the national high school graduation rate might appear to be a straightforward task but in reality, it is not so easy because of the measurement issues discussed in this paper. When the same definition of what it means to be a "high school graduate" is applied to comparable populations, we show that all major data sources produce the same levels and trends in graduation over the past 40 years.

Biases in both data and methodology that we document in this article are the cause of the large discrepancies in estimates that appear in the recent literature. As others have shown, and we confirm, recent estimates based on CCD data are often biased significantly downward by growth in ninth-grade retentions. This problem can be avoided by using eighth-grade enrollment as the base and we show that this estimator aligns with estimates from other data sources.

The most significant source of bias comes from including GED recipients as high school graduates. In recent years, their inclusion has biased graduation rates upwards of 7-8 percentage points. The exclusion of the military population from CPS data used to estimate the status 
completion rate has little impact on the estimates. Exclusion of incarcerated populations greatly affects the black male rate.

Especially striking are the comparisons in graduation rates between minorities and whites. While our estimated black graduation rate is 15 percentage points higher than the $50 \%$ rate reported in many recent studies, it is also 15 points lower than the NCES status completion rate. About 65\% of blacks and Hispanics leave secondary schooling with a diploma. An additional 5\% eventually receive a regular diploma through a variety of job training and adult education programs. Officially, white and minority high school completion rates have converged since the early 1970s. However, the official estimates are based on the civilian non-institutional population using CPS data and do not count those who are in prison. We show that when we count GED recipients as dropouts (incarcerated or not), there is little convergence in high school graduation rates between whites and minorities over the past 35 years. A significant portion of the convergence reported in the official statistics is due to black males obtaining GED credentials in prison.

The decline in high school graduation is important for understanding the recent slowdown in the growth of college attendance and completion and the growing gender difference in college attainment. In the first half of the $20^{\text {th }}$ century, growth in high school graduation was the driving force behind increased college enrollments. The decline in high school graduation since 1970 has flattened college attendance and completion rates as well as the skill attainment of the U.S. workforce. To increase the skill levels of the future workforce, America needs to confront a large and growing dropout problem.

James J. Heckman, University of Chicago, University College Dublin and the American Bar Foundation

Paul A. LaFontaine, American Bar Foundation 


\section{References}

Autor, David H., Lawrence F. Katz, and Melissa S. Kearney, "Rising Wage Inequality: The Role of Composition and Prices," NBER Technical Working Paper 11627, (Cambridge, MA: National Bureau of Economic Research, 2005).

Blumstein, Alfred, and Allen J. Beck, "Population Growth in the U.S. Prisons, 1980-1996," Crime and Justice, 26 (2000), 17-61.

Bridgeland, John M., DiIulio Jr., John J., and Karen Burke Morison, "The Silent Epidemic: Perspectives of High School Dropouts," (The Bill and Melinda Gates Foundation, 2006).

Bureau of Labor Statistics, NLS Handbook 2001: The National Longitudinal Surveys, (Washington, DC: U.S. Department of Labor, 2001)

Cameron, Stephen V., and James J. Heckman, "The Nonequivalence of High School Equivalents," Journal of Labor Economics, 11 (1993), 1-47.

Card, David, and Thomas Lemieux, "Dropout and Enrollment Trends in the Post-War Period: What Went Wrong in the 1970s?" in Risky Behavior among Youths: An Economic Analysis, J. Gruber, ed. (Chicago, IL: University of Chicago Press, 2001)

Center for Human Resource Research, NLSY97 User's Guide: A Guide to the Rounds 1-9 Data, National Longitudinal Survey of Youth 1997, (Columbus, OH: Ohio State University, 2006)

Center for Human Resource Research, NLSY79 Child and Young Adult Data User's Guide, (Columbus, OH: Ohio State University, 2004)

Chaplin, Duncan, "Tassels on the Cheap," Education Next, 2 (2002), 24-29.

Curtin, Thomas R., Steven J. Ingels, Shiying Wu, Ruth Heuer, and Jeffrey Owings, User's Manual, 2002, National Educational Longitudinal Study of 1988: Base-Year to Fourth Follow-Up Data File User's 
Manual, (Washington, DC: U.S. Department of Education, Office of Educational Research and Improvement, 2002)

Finn, Chester E., Jr., "The High School Dropout Puzzle," Public Interest, 87 (1987), 3-22.

Gensowski, Miriam, "GEDs and Prison," in The GED and the Problem of Noncognitive Skills in America, James J. Heckman, and Paul LaFontaine, eds. (Chicago, IL: University of Chicago Press, 2008)

Goldin, Claudia, and Lawrence F. Katz, "The 'Virtues' of the Past: Education in the First Hundred Years of the New Republic," NBER Working Papers 9958, (Cambridge, MA: National Bureau of Economic Research, Inc., 2003).

Goldin, Claudia, Lawrence F. Katz, and Ilyana Kuziemko, "The Homecoming of American College Women: The Reversal of the College Gender Gap," Journal of Economic Perspectives, 20 (2006), 133156.

Greene, Jay P., "High School Graduation Rates in the United States," Center for Civic Innovation at the Manhattan Institute with Black Alliance for Educational Options Civic Report 31, (New York, 2001).

Heckman, James J., and Paul LaFontaine, The GED and the Problem of Noncognitive Skills in America, (Chicago: University of Chicago Press, 2008) Forthcoming.

Heckman, James J., and Paul LaFontaine, "Bias Corrected Estimates of GED Returns," Journal of Labor Economics, 24 (2006), 661-700.

Heckman, James J., and Yona Rubinstein, "The Importance of Noncognitive Skills: Lessons from the GED Testing Program," American Economic Review, 91 (2001), 145-149.

Laird, Jennifer, Gregory Kienzl, Matthew DeBell, and Chris Chapman, "Dropout Rates in the United States: 2005," National Center for Education Statistics, Institute of Education Sciences NCES 2007-059, (Washington, DC: 2007). 
Laurence, Janet, "The Military Performance of GED Holders," in The GED and the Problem of Noncognitive Skills in America, James J. Heckman, and Paul LaFontaine, eds. (Chicago: University of Chicago Press, 2008) Forthcoming.

Lochner, Lance J., and Enrico Moretti, "The Effect of Education on Crime: Evidence from Prison Inmates, Arrests, and Self-Reports," American Economic Review, 94 (2004), 155-189.

Losen, Daniel J., Gary Orfield, Johanna Wald, and Christopher B. Swanson, Losing our Future: How Minority Youth are being Left Bebind by the Graduation Rate Crisis, (New York: Urban Institute; Advocates for Children of New York, 2004)

Mauer, Marc, The Crisis of the Young African American Male and the Criminal Justice System, (Washington, D.C: Sentencing Project, 1999)

Miao, Jing, and Walt Haney, "High School Graduation Rates: Alternative Methods and Implications," Education Policy Analysis Archives, 12 (2004), 1-68.

Miller, Shawn, The National Longitudinal Surveys NLSY79 User's Guide 1979-2002. (Washington, DC: Bureau of Labor Statistics, U.S. Department of Labor, 2004).

Mishel, Lawrence R., and Joydeep Roy, Rethinking High School Graduation Rates and Trends, (Washington, D.C: Economic Policy Institute, 2006)

National Center for Education Statistics, "National Education Longitudinal Study of 1988 (NELS:88) " (Washington, DC: National Center for Education Statistics, Institute of Education Sciences, 2002), http://nces.ed.gov/surveys/nels88/.

Quinn, Lois, "The Origins and Growth of GED Testing," in The GED and the Problem of Noncognitive Skills in America, James J. Heckman, and Paul LaFontaine, eds. (Chicago, IL: University of Chicago Press, 2008) Forthcoming. 
Scanniello, Nicole, "Comparison of ACS and ASEC Data on Educational Attainment: 2004," (Washington, DC: U.S. Census Bureau, Housing and Household Economics Statistics Division, 2007), http://www.census.gov/acs/www/Downloads/ACS ASEC Attainment.doc.

Schochet, Peter Z., John A. Burghardt, and Steven Glazerman, National Job Corps Study the Impacts of Job Corps on Participants' Employment and Related Outcomes, (Washington, D.C: U.S. Dept. of Labor, Employment and Training Administration, Office of Policy and Research, 2001)

State of New Jersey, Department of Education, "Historical Report Card Data 2005," (Trenton, NJ: State of New Jersey, Department of Education, 2006), http://education.state.nj.us/rc/2005/index.html.

Sum, Andrew, Paul Harrington, Charles Bartishevich, Neeta Fogg, Ishwar Khatiwada, Jacqui Motroni, Sheila Palma, Nathan Pond, Paulo Tobar, and Mykhaylo Trub'skyy, "The Hidden Crisis in the High School Dropout Problems of Young Adults in the U.S.: Recent Trends in overall School Dropout Rates and Gender Differences in Dropout Behavior," (Washington, DC: The Business Roundtable, 2003).

Swanson, Christopher B., Who Graduates? Who Doesn't? A Statistical Portrait of Public High School Graduation, Class of 2001, (Washington, D.C: Urban Institute Education Policy Center, 2004) Swanson, Christopher B., "State Approaches for Calculating High School Graduation Rates," NCLB Implementation Report (Washington, DC: Urban Institute Education Policy Center, 2003).

Swanson, Christopher B., and Duncan Chaplin, "Counting High School Graduates when Graduates Count: Measuring Graduation Rates Under the High Stakes of NCLB," (Washington, DC: Urban Institute Education Policy Center, 2003).

United States Congress, "No Child Left Behind Act of 2001," 20 USC 6301. Public Law 107-110, 2001), 
United States National Commission on Excellence in Education, A Nation at Risk: The Imperative for Educational Reform. A Report to the Nation and the Secretary of Education, United States Department of Education, (Washington, D.C: National Commission on Excellence in Education, 1983)

Warren, John R., "State-Level High School Completion Rates: Concepts, Measures, and Trends," Education Policy Analysis Archives, 13 (2005), 1-34.

Western, Bruce, and Becky Pettit, "Incarceration and Racial Inequality in Men's Employment," Industrial and Labor Relations Review, 54 (2000), 3-16. 
Notes

${ }^{*}$ This research was supported by the Committee on Economic Development PAES Project, the Pew Foundation, NIH R01-

HD043411, NSF SES-024158 and the American Bar Foundation. The views expressed in this paper are those of the authors and not necessarily those of the funders listed here. We thank Amanda Edwards, Lynne Heckman, Kathryn McLellan, Derek Neal, Steve Raudenbush, and Diane Schanzenbach for helpful comments. Mary Mei, Alex Volfovsky and William Cha provided very helpful research assistance. Corresponding author: James J. Heckman, University of Chicago, Department of Economics, 1126 E. 59th Street, Chicago IL 60637. Telephone: (773) 702-0634; Fax: (773) 702-8490. Email: jjh@uchicago.edu.

${ }_{1}$ See Figure S.1 in the Web Appendix (http://jenni.uchicago.edu/estimating hsgraduation/) based on Autor, Katz and Kearney (2005).

${ }^{2}$ These numbers are not available by race.

${ }^{3}$ This reversal coincides temporally with the implementation of federally mandated graduation rate monitoring under the No Child Left Behind Act (NCLB). We discuss this point and the evidence that schools may be "gaming" the system in more detail later in the text.

${ }_{4}^{4}$ For a sample, see the heated debate in the popular press in May 2006 www.washingtonpost.com/wp-dyn/content/article/2006/05/22/AR2006052201187.html; www.washingtonpost.com/wp-dyn/content/article/2006/05/22/AR2006052201197.html; and www.washingtonpost.com/wp-dyn/content/article/2006/05/22/AR2006052201189.html.

${ }^{5}$ In practice, there is some flexibility built into No Child Left Behind for states to define their own graduation standards. The law further states that "Another definition, developed by the State and approved by the Secretary in the State plan" (Title I Final Regulations, Sec. 200.19 (a)(1)(i)(B)) could also be employed. See Swanson (2003) for a detailed discussion of the implementation of NCLB graduation measures in each state. 
${ }^{6}$ See our Web Appendix Part A for a more detailed description of CPS and Census data.

${ }_{7}$ See Table S.1 in the Web Appendix. at http://jenni.uchicago.edu/estimating hsgraduation/ for a more detailed description of this calculation. Laird, et al. (2007) use a similar method as we employ here.

${ }^{8}$ Mishel and Roy (2006) perform a similar calculation and conclude that the CPS is not substantially biased by these factors. However, they do not simultaneously correct for all of the biases we discuss to show the total effect of the biases. If they had done so, they would have reached a conclusion similar to ours.

${ }^{9}$ The population totals used to compute our Census graduation rates are listed in Web Appendix Tables A.1 through A.7.

${ }^{10}$ Appendix Figure S.2 shows that the average age of GED recipients at the time they pass the GED test adjusted for the age composition of the population has declined sharply since the beginning of the program. While the changing demographic structure connected with the Baby Boom and the Baby Bust accounts for a small part of the time series of the age pattern of GED test takers, most of the decline in the average age is due to other factors.

${ }^{11}$ See Web Appendix Figure S.3

${ }_{12}^{12}$ See http://www.state.nj.us/education/students/ged/ged11.htm for more details about the New Jersey GED program.

${ }^{13}$ It is not possible to fully account for the alternative completers who are issued state diplomas with the available data. The graduation rates we report in this paper are close to upper bounds since we lack information to fully account for these completers. This is true of both the 
administrative and survey data estimates. NCLB likely exacerbates this potential source of bias since it increases the incentives for states to raise reported graduation rates by any means possible. For instance, when New Jersey increased the difficulty of the state exit exam, the numbers enrolled in Special Review Assessment (SRA) diploma program increased dramatically.

${ }_{14}$ New Jersey, as well as most other states with high stakes exit exams, offers an alternative program for those who fail the High School Proficiency Assessment (HSPA). The SRA program administers diplomas based on a series of untimed locally administered tests similar in content to the GED and distinct from the HSPA. In $2006,12 \%$ of all graduates and over $1 / 3$ in urban areas came through the SRA program (See State of New Jersey Department of Education [2006], 2005-06 School Report Card).

${ }^{15}$ This has important implications for a large body of economic research devoted to differences in earnings between minorities and whites. Substantial gaps remain in the market wages of minorities compared to those for whites. Part of this gap is a result of minorities obtaining less valuable GED credentials rather than high school diplomas. See Heckman and LaFontaine (2008) for this evidence.

${ }_{16}$ See Web Appendix Table S.2.

${ }_{17}$ The estimated graduation rates for each race and gender group of this cohort are shown in Table A.1 in the Web Appendix.

${ }_{18}$ The percent distribution of non-institutional, non-military GED recipients by race and sex is calculated from CPS October data. See the Web Appendix for further details. 
${ }^{19}$ See Web Appendix Figure S.4. This increase is not the result of an increase in violent crimes, but instead is due to mandatory and longer prison sentencing for non-violent drug offenders and repeat offenders. See Blumstein and Beck (2000) and Mauer (1999) for a discussion of this point.

${ }^{20}$ The total incarcerated population is even greater than the number reported here as the figure excludes those who are serving short-term sentences or awaiting trial in local jails. The breakdown of the incarcerated population by type of institution and education for recent years is documented in Web Appendix Tables A.10-A.17.

${ }^{21}$ See Web Appendix Tables A.13-A.16.

${ }_{22}$ Mishel and Roy (2006) claim that including the incarcerated population only has a minimal impact on the estimated black-white gap in high school graduation. However, they do not account for the fact that over 50 percent of the overall high school completion category in the incarcerated sample in the Census is composed of GED recipients, and the rate is even higher among young black males.

${ }^{23}$ See Web Appendix Table A.18.

${ }^{24}$ Web Appendix Figure S.5 shows this was not always the case.

${ }_{25}$ See Web Appendix Figure S.6 for trends on immigration.

${ }_{26}$ See Web Appendix Figure S.7.

${ }^{27}$ For instance, suppose the CPS survey estimates 250,000 black males ages 20-24 in the civilian non-institutional while Census bureau estimates show there should be 500,000 in this category. The CPS weights for this category are doubled to account for the underestimate. 
${ }^{28}$ Census coverage is benchmarked against estimated population totals from administrative birth, death and immigration records.

${ }_{29}$ See the Web Appendix A for a detailed discussion of the CPS March supplement.

${ }^{30}$ The most relevant comparison is between the CPS March and IPUMS surveys since they are closest in timeframe. The IPUMS point of reference is April $1^{\text {st }}$ while the CPS questionnaire is administered in the third week of March. In addition, the weights for the CPS March survey are based on the 2000 Census population estimates while those for the October survey are based on the 1990 Census estimates. Calculations using CPS October data yield similar conclusions to those found using the March data.

${ }_{31}$ See Web Appendix Table A.20 in the Web Appendix for the complete disaggregated estimates of the educational distributions across the two data sources.

${ }^{32}$ See Web Appendix Table A.20 for the tests of equality by race and sex.

${ }_{33}$ There is no way to analyze the role of survey administration with the existing data. CATI and CAPI interviews are performed in the ACS data but only for the select sample of people who do not respond to the mail questionnaire.

${ }^{34}$ It should be noted that these result are computed in the year 2000 and will not hold for the entire status completion rate time series since GED test taking, incarceration, immigration and other factors have changed considerably over the past 40 years.

${ }_{35}$ These administrative data-based-graduation estimators include the Swanson Cumulative Promotion Index (CPI) and the Greene Method. See Web Appendix A for details on the construction of these various estimators. 
${ }_{36}$ For some sources that make this claim see Swanson and Chaplin (2003); Greene (2001); Losen, et al. (2004) and Bridgeland, DiIulio and Morison (2006).

${ }^{37}$ NCLB provides a strong incentive for schools to end high school grade retention because under NCLB schools are supposed to report on-time graduation rates. This is defined as "The percentage of students, measured from the beginning of high school, who graduate from high school with a regular diploma...in the standard number of years”. Students who are held back and later graduate do not count under this definition.

${ }^{38}$ Census data include public and private schools while the CCD data are only for public schools. The data necessary to align the two sources more closely are not available.

39 An evaluation of Job Corps by Schochet, Burghardt and Glazerman (2001) finds that 5.3\% of Job Corps participants achieve high school diplomas within 48 months, while $41.6 \%$ GED certify. This focus on GED certification helps explain the estimated negative returns to Job Corps. The program has since shifted toward awarding more regular high school diplomas.

${ }^{40}$ For the details of these calculations see the Web Appendix A.

${ }^{41}$ See NLS Handbook 2001: The National Longitudinal Surveys (Bureau of Labor Statistics, 2001), NLSY79 Child and Young Adult Data User's Guide (Center for Human Resource Research, 2004), NLSY97 User's Guide: A Guide to the Rounds 1-9 Data National Longitudinal Survey of Youth 1997 (Center for Human Resource Research, 2006), Miller (2004) and National Education Longitudinal Study of 1988 (NELS 88) (National Center for Education Statistics, 2002).

${ }^{42}$ See http://nces.ed.gov/surveys/hsb/ and http://nces.ed.gov/surveys/nels88/ for data and documentation. These surveys are also discussed further in the Web Appendix. 
${ }^{43}$ See Web Appendix Figure S.8 for the race/sex distribution of ineligibles compared to the full NELS sample.

${ }^{44}$ This is the base year to fourth follow-up panel weight (F4BYPNW'T).

${ }_{45}$ For the base year ineligibles that were eligible for the third follow-up, we are able to compute the high school graduation rate directly. Those who are still not eligible by the third follow-up are assumed to graduate at the same rate as base year ineligibles that were out of sequence in the second follow-up. HSB base year ineligibles are assumed to graduate at the same rates by race and sex as NELS ineligibles.

${ }^{46}$ See the Web appendix for a description of this data source.

${ }_{47}$ There was a decline in college attendance for male high school graduates following the Vietnam War, during which college attendance provided a deferment from the draft during most of the war. 
Table I: HS Graduation Rate Estimates Across Various Longitudinal Data Sources

\begin{tabular}{|c|c|c|c|c|c|c|c|}
\hline & NLS68 & NLS79 & NLSY79 & HSB80 & NELS88 & NLSY97 & Add Health \\
\hline Cohort of Birth & $(1946-1950)$ & $(1957-1960)$ & $(1961-1964)$ & $(1962-1964)$ & $(1972-1974)$ & $(1980-1984)$ & $(1980-1982)$ \\
\hline \multicolumn{8}{|l|}{ A. Overall } \\
\hline All & $\begin{array}{c}81.8 \% \\
(.005)\end{array}$ & $\begin{array}{c}80.8 \% \\
(.006)\end{array}$ & $\begin{array}{c}77.9 \% \\
(.006)\end{array}$ & $\begin{array}{c}82.9 \% \\
(.005)\end{array}$ & $\begin{array}{c}83.1 \% \\
(.004)\end{array}$ & $\begin{array}{c}77.5 \% \\
(.004)\end{array}$ & $\begin{array}{c}77.5 \% \\
(.008)\end{array}$ \\
\hline Whites & $\begin{array}{c}84.6 \% \\
(.006)\end{array}$ & $\begin{array}{c}84.4 \% \\
(.008)\end{array}$ & $\begin{array}{c}80.8 \% \\
(.008)\end{array}$ & $\begin{array}{c}84.8 \% \\
(.006)\end{array}$ & $\begin{array}{c}85.5 \% \\
(.005)\end{array}$ & $\begin{array}{c}80.2 \% \\
(.006)\end{array}$ & $\begin{array}{c}79.7 \% \\
(.010)\end{array}$ \\
\hline Blacks & $\begin{array}{c}64.3 \% \\
(.013)\end{array}$ & $\begin{array}{c}69.7 \% \\
(.013)\end{array}$ & $\begin{array}{c}70.7 \% \\
(.011)\end{array}$ & $\begin{array}{c}78.8 \% \\
(.010)\end{array}$ & $\begin{array}{c}74.8 \% \\
(.011)\end{array}$ & $\begin{array}{c}69.1 \% \\
(.010)\end{array}$ & $\begin{array}{c}71.4 \% \\
(.018)\end{array}$ \\
\hline Hispanics & $\begin{array}{l}\ldots \\
\ldots\end{array}$ & $\begin{array}{c}60.9 \% \\
(.016)\end{array}$ & $\begin{array}{c}59.7 \% \\
(.015)\end{array}$ & $\begin{array}{c}71.2 \% \\
(.013)\end{array}$ & $\begin{array}{c}74.3 \% \\
(.012)\end{array}$ & $\begin{array}{c}72.3 \% \\
(.010)\end{array}$ & $\begin{array}{c}68.8 \% \\
(.025)\end{array}$ \\
\hline \multicolumn{8}{|l|}{ B. Males } \\
\hline All & $\begin{array}{c}81.4 \% \\
(.008)\end{array}$ & $\begin{array}{c}79.5 \% \\
(.009)\end{array}$ & $\begin{array}{c}74.4 \% \\
(.008)\end{array}$ & $\begin{array}{c}80.8 \% \\
(.007)\end{array}$ & $\begin{array}{c}82.0 \% \\
(.006)\end{array}$ & $\begin{array}{c}75.2 \% \\
(.006)\end{array}$ & $\begin{array}{c}75.0 \% \\
(.012)\end{array}$ \\
\hline Whites & $\begin{array}{c}84.3 \% \\
(.009)\end{array}$ & $\begin{array}{c}83.3 \% \\
(.011)\end{array}$ & $\begin{array}{c}78.0 \% \\
(.011)\end{array}$ & $\begin{array}{c}82.5 \% \\
(.012)\end{array}$ & $\begin{array}{c}84.2 \% \\
(.008)\end{array}$ & $\begin{array}{c}78.8 \% \\
(.008)\end{array}$ & $\begin{array}{c}76.8 \% \\
(.015)\end{array}$ \\
\hline Blacks & $\begin{array}{c}60.0 \% \\
(.018)\end{array}$ & $\begin{array}{c}65.7 \% \\
(.019)\end{array}$ & $\begin{array}{c}64.6 \% \\
(.017)\end{array}$ & $\begin{array}{c}76.0 \% \\
(.015)\end{array}$ & $\begin{array}{c}75.9 \% \\
(.014)\end{array}$ & $\begin{array}{c}63.4 \% \\
(.014)\end{array}$ & $\begin{array}{c}67.7 \% \\
(.028)\end{array}$ \\
\hline Hispanics & $\begin{array}{l}\ldots \\
\ldots\end{array}$ & $\begin{array}{c}60.1 \% \\
(.024)\end{array}$ & $\begin{array}{c}54.5 \% \\
(.022)\end{array}$ & $\begin{array}{c}71.4 \% \\
(.017)\end{array}$ & $\begin{array}{c}71.2 \% \\
(.015)\end{array}$ & $\begin{array}{c}69.7 \% \\
(.015)\end{array}$ & $\begin{array}{c}69.0 \% \\
(.037)\end{array}$ \\
\hline \multicolumn{8}{|l|}{ B. Females } \\
\hline All & $\begin{array}{c}82.1 \% \\
(.008)\end{array}$ & $\begin{array}{c}82.1 \% \\
(.008)\end{array}$ & $\begin{array}{c}81.5 \% \\
(.008)\end{array}$ & $\begin{array}{c}85.0 \% \\
(.006)\end{array}$ & $\begin{array}{c}84.2 \% \\
(.006)\end{array}$ & $\begin{array}{c}79.9 \% \\
(.006)\end{array}$ & $\begin{array}{c}79.9 \% \\
(.010)\end{array}$ \\
\hline Whites & $\begin{array}{c}84.9 \% \\
(.009)\end{array}$ & $\begin{array}{c}85.5 \% \\
(.010)\end{array}$ & $\begin{array}{c}83.8 \% \\
(.010)\end{array}$ & $\begin{array}{c}87.1 \% \\
(.009)\end{array}$ & $\begin{array}{c}86.8 \% \\
(.007)\end{array}$ & $\begin{array}{c}81.8 \% \\
(.008)\end{array}$ & $\begin{array}{c}82.7 \% \\
(.012)\end{array}$ \\
\hline Blacks & $\begin{array}{c}66.9 \% \\
(.018)\end{array}$ & $\begin{array}{c}73.3 \% \\
(.017)\end{array}$ & $\begin{array}{c}77.0 \% \\
(.015)\end{array}$ & $\begin{array}{c}81.4 \% \\
(.014)\end{array}$ & $\begin{array}{c}73.5 \% \\
(.013)\end{array}$ & $\begin{array}{c}75.0 \% \\
(.013)\end{array}$ & $\begin{array}{c}75.3 \% \\
(.022)\end{array}$ \\
\hline Hispanics & $\begin{array}{l}\ldots \\
\ldots \\
\end{array}$ & $\begin{array}{c}61.7 \% \\
(.023) \\
\end{array}$ & $\begin{array}{c}65.4 \% \\
(.021) \\
\end{array}$ & $\begin{array}{c}70.9 \% \\
(.015) \\
\end{array}$ & $\begin{array}{c}77.1 \% \\
(.013) \\
\end{array}$ & $\begin{array}{c}75.2 \% \\
(.014) \\
\end{array}$ & $\begin{array}{c}68.5 \% \\
(.035) \\
\end{array}$ \\
\hline
\end{tabular}

Source: Authors' calculations based on NLSY, NELS and HSB data. GED recipients are not counted as high school graduates in all calculations. All outcomes are weighted. The AddHealth data is restricted to those enrolled in the 7th and 8th grades in the initial survey. Hispanic samples are too small in NLS68 data to obtain reliable estimates. Standard errors in parentheses. 
Table II. Comparison of HSB, NLSY79, Census, CPS and CCD Data Estimates

\begin{tabular}{|c|c|c|c|c|c|c|c|c|c|c|}
\hline \multirow[b]{2}{*}{ Enrollments } & \multicolumn{5}{|c|}{ Overall } & \multicolumn{5}{|c|}{ Blacks } \\
\hline & HSB & NLSY79 & Census & CPS & $\mathrm{CCD}$ & HSB & NLSY79 & Census & CPS & $\mathrm{CCD}$ \\
\hline 1980 Public 10th Grade Enrollment & $3,424,050$ & $3,630,119$ & $3,575,616$ & $3,640,980$ & $3,532,000$ & 492,300 & 553,071 & 548,688 & 596,512 & $\ldots$ \\
\hline 1980 Private 10th Grade Enrollment & 356,877 & 278,339 & 340,374 & 303,700 & $\ldots$ & 17,039 & 6,919 & 21,713 & 13,069 & $\ldots$ \\
\hline 1980 Total 10th Grade Enrollment & $3,780,927$ & $3,908,458$ & $3,915,990$ & $3,944,680$ & $\ldots$ & 509,339 & 559,990 & 570,401 & 609,581 & $\ldots$ \\
\hline \multicolumn{11}{|l|}{ Pre-10th Grade Dropouts } \\
\hline Total & $\ldots$ & 159,301 & 154,072 & 166,459 & $\ldots$ & $\ldots$ & 17,345 & 20,396 & 21,029 & $\ldots$ \\
\hline as $\%$ of Cohort size (by race) & $\ldots$ & $3.92 \%$ & $3.79 \%$ & $4.05 \%$ & $\ldots$ & $\ldots$ & $3.00 \%$ & $3.45 \%$ & $3.33 \%$ & $\ldots$ \\
\hline Total Who Never Received HS Diploma & $\ldots$ & 144,786 & $\ldots$ & $\ldots$ & $\ldots$ & $\ldots$ & 17,345 & $\ldots$ & $\ldots$ & $\ldots$ \\
\hline \multicolumn{11}{|l|}{ Estimated Base Year Ineligibles } \\
\hline Total & 135,063 & $\cdots$ & $\ldots$ & $\ldots$ & $\ldots$ & 61,062 & .. & $\ldots$ & $\ldots$ & ... \\
\hline as $\%$ of Cohort Size & $3.45 \%$ & $\ldots$ & $\ldots$ & $\ldots$ & $\ldots$ & $10.71 \%$ & $\ldots$ & $\ldots$ & $\ldots$ & $\ldots$ \\
\hline \multicolumn{11}{|l|}{ Graduates } \\
\hline Final Cohort Size at Fourth Follow-Up & $3,757,767$ & $\ldots$ & $\ldots$ & $\ldots$ & $\ldots$ & 496,105 & $\ldots$ & $\ldots$ & $\ldots$ & $\ldots$ \\
\hline 1982 High School Graduates & $2,925,162$ & $2,988,235$ & $\ldots$ & $2,709,071$ & $2,995,000$ & 344,019 & 357,717 & $\ldots$ & 327,832 & $\ldots$ \\
\hline Total Cohort High School Graduates & $3,115,189$ & $3,137,081$ & $\ldots$ & $\ldots$ & $\ldots$ & 390,931 & 376,555 & $\ldots$ & $\ldots$ & $\cdots$ \\
\hline \multicolumn{11}{|l|}{ Graduation Rates } \\
\hline Cohort Rate & $79.82 \%$ & $77.40 \%$ & $77.92 \%$ & $\ldots$ & $76.54 \%$ & $76.14 \%$ & $65.22 \%$ & $63.94 \%$ & $\ldots$ & $\ldots$ \\
\hline On-time Cohort Rate & $74.51 \%$ & $73.72 \%$ & $\ldots$ & $\ldots$ & $\ldots$ & $65.32 \%$ & $61.96 \%$ & $\ldots$ & $\ldots$ & $\ldots$ \\
\hline \multirow[t]{2}{*}{ Final Graduation Rate } & $78.60 \%$ & $77.40 \%$ & $77.92 \%$ & $\ldots$ & $76.54 \%$ & $71.97 \%$ & $65.22 \%$ & $63.94 \%$ & $\ldots$ & $\ldots$ \\
\hline & \multicolumn{5}{|c|}{ Whites } & \multicolumn{5}{|c|}{ Hispanics } \\
\hline Enrollments & HSB & NLSY79 & Census & CPS & CCD & HSB & NLSY79 & Census & CPS & $\mathrm{CCD}$ \\
\hline Public 10th Grade Enrollment & $2,573,072$ & $2,679,389$ & $2,682,678$ & $2,724,248$ & $\ldots$ & 254,258 & 254,517 & 263,152 & 248,716 & $\ldots$ \\
\hline Private 10th Grade Enrollment & 309,931 & 236,607 & 288,021 & 278,069 & $\ldots$ & 22,653 & 34,813 & 23,195 & 10,007 & $\ldots$ \\
\hline Total 10th Grade Enrollment & $2,883,003$ & $2,915,996$ & $2,970,699$ & $3,002,317$ & $\ldots$ & 276,911 & 289,330 & 286,347 & 258,723 & $\ldots$ \\
\hline \multicolumn{11}{|l|}{ Pre-10th Grade Dropouts } \\
\hline Total & $\ldots$ & 115,476 & 102,616 & 134,766 & $\ldots$ & $\ldots$ & 26,480 & 26,737 & 27,167 & $\ldots$ \\
\hline as $\%$ of Cohort size (by race) & $\ldots$ & $3.81 \%$ & $3.34 \%$ & $4.30 \%$ & $\ldots$ & $\ldots$ & $8.38 \%$ & $8.54 \%$ & $9.50 \%$ & $\ldots$ \\
\hline Total Who Never Received HS Diploma & $\ldots$ & 100,961 & $\ldots$ & $\ldots$ & $\ldots$ & $\ldots$ & 26,480 & $\ldots$ & $\ldots$ & $\ldots$ \\
\hline \multicolumn{11}{|l|}{ Estimated Base Year Ineligibles } \\
\hline Total & 87,696 & $\ldots$ & $\ldots$ & $\cdots$ & $\ldots$ & 9,436 & $\cdots$ & $\cdots$ & $\cdots$ & $\cdots$ \\
\hline as $\%$ of Cohort Size & $2.95 \%$ & $\ldots$ & $\ldots$ & $\ldots$ & $\ldots$ & $3.30 \%$ & $\ldots$ & $\ldots$ & $\ldots$ & $\ldots$ \\
\hline \multicolumn{11}{|l|}{ Graduates } \\
\hline Final Cohort Size at Fourth Follow-Up & $2,876,611$ & $\ldots$ & $\ldots$ & $\ldots$ & $\ldots$ & 296,273 & $\ldots$ & $\ldots$ & $\ldots$ & $\ldots$ \\
\hline 1982 High School Graduates & $2,319,837$ & $2,381,901$ & $\ldots$ & $2,179,253$ & $\ldots$ & 194,971 & 170,405 & $\ldots$ & 140,494 & $\ldots$ \\
\hline Total Cohort High School Graduates & $2,439,366$ & $2,476,871$ & $\ldots$ & $\ldots$ & $\ldots$ & 210,839 & 193,549 & $\ldots$ & $\ldots$ & $\ldots$ \\
\hline \multicolumn{11}{|l|}{ Graduation Rates } \\
\hline Cohort Rate & $81.92 \%$ & $82.10 \%$ & $81.58 \%$ & $\ldots$ & $\ldots$ & $65.33 \%$ & $61.29 \%$ & $62.63 \%$ & $\ldots$ & $\ldots$ \\
\hline On-time Cohort Rate & $77.74 \%$ & $78.95 \%$ & $\ldots$ & $\ldots$ & $\ldots$ & $64.26 \%$ & $53.96 \%$ & $\ldots$ & $\ldots$ & $\ldots$ \\
\hline Final Graduation Rate & $80.83 \%$ & $82.10 \%$ & $81.58 \%$ & $\ldots$ & $\ldots$ & $64.74 \%$ & $61.29 \%$ & $62.63 \%$ & $\ldots$ & $\ldots$ \\
\hline
\end{tabular}

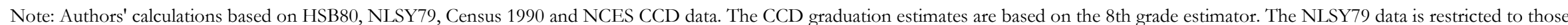

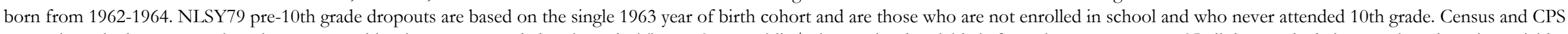

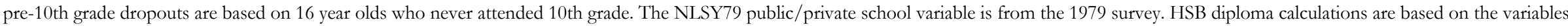

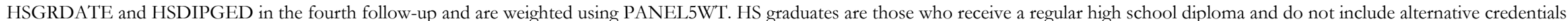
such as the GED. The "other race" category is not shown and therefore totals by race do not sum to overall totals. CPS diplomas are total credentials issued to $16-24$ year olds in

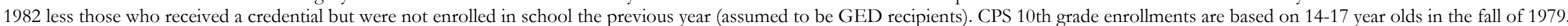

Census graduation estimates are those for the HSB cohort shown in the previous section. CCD graduates include all regular diplomas issued to public and private school graduates in 1982. Base year

ineligible graduation rates by race estimated from NELS data. 
Table III. Comparison of NELS, CPS October, IPUMS and CCD Data Estimates

\begin{tabular}{|c|c|c|c|c|c|c|c|c|}
\hline \multirow[b]{2}{*}{ Enrollments } & \multicolumn{4}{|c|}{ Overall } & \multicolumn{4}{|c|}{ Blacks } \\
\hline & NELS & CPS & Census & $\mathrm{CCD}$ & NELS & CPS & Census & CCD \\
\hline 1988 Public 8th Grade Enrollment & $2,645,844$ & $2,808,521$ & $\ldots$ & $2,839,000$ & 368,611 & 476,338 & $\ldots$ & $\ldots$ \\
\hline 1988 Private 8th Grade Enrollment & 362,236 & 312,062 & $\ldots$ & $\ldots$ & 27,859 & 22,342 & $\ldots$ & $\ldots$ \\
\hline 1988 Total 8th Grade Enrollment & $3,008,080$ & $3,120,583$ & $\ldots$ & $\ldots$ & 396,470 & 498,681 & $\ldots$ & $\ldots$ \\
\hline 1990 Public 10th Grade Enrollment & $2,744,014$ & $2,960,799$ & $2,981,183$ & $2,895,549$ & 374,291 & 510,126 & 483,163 & $\ldots$ \\
\hline 1990 Total 10th Grade Enrollment & $3,023,406$ & $3,161,876$ & $3,251,853$ & $\ldots$ & 396,009 & 531,963 & 507,585 & $\ldots$ \\
\hline \multicolumn{9}{|l|}{ Base Year Ineligibles } \\
\hline Total & 148,352 & $\ldots$ & $\ldots$ & $\ldots$ & 23,440 & $\ldots$ & $\ldots$ & $\ldots$ \\
\hline as $\%$ of Cohort Size (by race) & $4.70 \%$ & $\ldots$ & $\ldots$ & $\ldots$ & $5.58 \%$ & $\ldots$ & $\ldots$ & $\ldots$ \\
\hline 1988 Total 8th Grade Enrollment Including Ineligibles & $3,156,432$ & $3,120,583$ & $\ldots$ & $3,151,062$ & 419,910 & 498,681 & $\ldots$ & $\ldots$ \\
\hline Graduates & & $\ldots$ & $\ldots$ & $\ldots$ & & $\ldots$ & $\ldots$ & $\ldots$ \\
\hline Final Cohort Size at Third Follow-Up & $3,201,742$ & $\ldots$ & $\ldots$ & $\ldots$ & 436,716 & $\ldots$ & $\ldots$ & $\ldots$ \\
\hline 1992 High School Graduates & $2,473,325$ & $2,244,707$ & $\ldots$ & $2,478,000$ & 284,963 & 325,471 & $\ldots$ & 306,054 \\
\hline Total High School Graduates for Cohort & $2,587,540$ & $\ldots$ & $\ldots$ & $\ldots$ & 311,718 & $\ldots$ & $\ldots$ & $\ldots$ \\
\hline \multicolumn{9}{|l|}{ Graduation Rates } \\
\hline 8th Grade Estimator & $78.36 \%$ & $71.93 \%$ & $\ldots$ & $\ldots$ & $67.86 \%$ & $65.27 \%$ & $\ldots$ & $61.37 \%$ \\
\hline Initial Cohort Rate & $80.82 \%$ & $\ldots$ & $\ldots$ & $\ldots$ & $71.38 \%$ & $\ldots$ & $\ldots$ & $\ldots$ \\
\hline On-time Cohort Rate & $77.25 \%$ & $\ldots$ & $\ldots$ & $\ldots$ & $65.25 \%$ & $\ldots$ & $\ldots$ & $\ldots$ \\
\hline \multirow[t]{2}{*}{ Final Rate Including All Ineligibles } & $79.67 \%$ & $71.93 \%$ & $79.16 \%$ & $79.41 \%$ & $70.15 \%$ & $65.27 \%$ & $68.89 \%$ & $64.05 \%$ \\
\hline & \multicolumn{4}{|c|}{ Whites } & \multicolumn{4}{|c|}{ Hispanics } \\
\hline Enrollments & NELS & CPS & Census & CCD & NELS & CPS & Census & CCD \\
\hline 1988 Public 8th Grade Enrollment & $1,776,355$ & $1,964,843$ & $\ldots$ & & 280,462 & 318,194 & $\ldots$ & $\ldots$ \\
\hline 1988 Private 8th Grade Enrollment & 276,413 & 249,414 & $\ldots$ & $\ldots$ & 29,416 & 14,830 & $\ldots$ & $\ldots$ \\
\hline 1988 Total 8th Grade Enrollment & $2,052,768$ & $2,214,256$ & $\ldots$ & $\ldots$ & 309,878 & 333,024 & $\ldots$ & $\ldots$ \\
\hline 1990 Public 10th Grade Enrollment & $1,847,600$ & $2,010,708$ & $2,006,352$ & $\ldots$ & 306,415 & 332,377 & 354,527 & $\ldots$ \\
\hline 1990 Total 10th Grade Enrollment & $2,063,265$ & $2,171,737$ & 2,212,999 & $\ldots$ & 326,756 & 339,666 & 381,371 & $\ldots$ \\
\hline \multicolumn{9}{|l|}{ Base Year Ineligibles } \\
\hline Total & 70,319 & $\ldots$ & $\ldots$ & $\ldots$ & 28,039 & $\ldots$ & $\ldots$ & $\ldots$ \\
\hline as $\%$ of Cohort Size (by race) & $3.31 \%$ & $\ldots$ & $\ldots$ & $\ldots$ & $8.30 \%$ & $\ldots$ & $\ldots$ & $\ldots$ \\
\hline 1988 Total 8th Grade Enrollment Including Ineligibles & $2,123,087$ & $2,214,256$ & $\ldots$ & $\ldots$ & 337,917 & 333,024 & $\ldots$ & $\ldots$ \\
\hline \multicolumn{9}{|l|}{ Graduates } \\
\hline Final Cohort Size at Third Follow-Up & $2,218,487$ & $\ldots$ & $\ldots$ & $\ldots$ & 362,124 & $\ldots$ & $\ldots$ & $\ldots$ \\
\hline 1992 High School Graduates & $1,799,708$ & $1,628,077$ & $\ldots$ & $1,830,266$ & 242,817 & 174,977 & $\ldots$ & 201,720 \\
\hline Total High School Graduates for Cohort & $1,862,766$ & $\ldots$ & $\ldots$ & $\ldots$ & 263,062 & $\ldots$ & $\ldots$ & $\ldots$ \\
\hline \multicolumn{9}{|l|}{ Graduation Rates } \\
\hline 8th Grade Estimator & $84.77 \%$ & $73.53 \%$ & $\ldots$ & $82.46 \%$ & $71.86 \%$ & $52.54 \%$ & $\ldots$ & $\ldots$ \\
\hline Initial Cohort Rate & $83.97 \%$ & $\ldots$ & $\ldots$ & $\ldots$ & $72.64 \%$ & $\ldots$ & $\ldots$ & $\ldots$ \\
\hline On-time Cohort Rate & $81.12 \%$ & $\ldots$ & $\ldots$ & $\ldots$ & $67.05 \%$ & $\ldots$ & $\ldots$ & $\ldots$ \\
\hline Final Rate Including All Ineligibles & $83.06 \%$ & $73.53 \%$ & $82.75 \%$ & $82.46 \%$ & $71.91 \%$ & $52.54 \%$ & $62.32 \%$ & $61.77 \%$ \\
\hline
\end{tabular}

Note: Authors' calculations based on NELS88, Census 1990, 2000 and NCES CCD data. The final 8th Grade enrollment estimate for the CCD data includes the 8th grade private enrollment estimate from the CPS October data. NELS 10th grade enrollment counts include those who were enrolled in the spring and fall who dropped out before the spring survey round in order to be comparable to fall enrollment counts in other data. NELS base year estimates are based on the base year race variable and base year weight. NELS third follow-up calculations are based on the variables F3RACE, F3DIPLOM, F3HSCPDT and weighted using F3QWT. Base year ineligibles who were still ineligible by the third follow-up are assumed to have the graduation rates of sampled base vear ineligibles who were out of modal grade sequence in the second follow-up. CPS graduates are those ages 16-24 who received a regular HS diploma in 1992. CPS 8th grade enrollment counts are for 12-15 year olds in the fall of 1987. CPS 10th grade enrollment counts are for 14-17 year olds in the fall of 1989. Missing CCD data by race are imputed for all states to obtain final diploma counts. CCD diplomas inlcude all regular diplomas issued to public and private school graduates in 1992.

Private school diplomas by race are distributed according to 10th grade enrollment counts by race. The "other race" category is not shown and therefore totals by race do not sum to overal totals. The CCD graduation estimates by race are base on the same sample as those shown in Figure VIII to limit the effects of imputation on the estimates. Census graduation estimates are those for the NELS cohort shown in the previous section. 
Table IV. Decomposition of the Change in College Graduation between the 1900 and 1980 Birth Cohorts

\begin{tabular}{|c|c|c|c|c|c|c|c|c|c|c|c|c|}
\hline \multirow[b]{2}{*}{ A. Probabilities } & \multicolumn{4}{|c|}{ All } & \multicolumn{4}{|c|}{ Males } & \multicolumn{4}{|c|}{ Females } \\
\hline & $\begin{array}{l}\Delta \text { Probability } \\
\text { (HS) }\end{array}$ & $\begin{array}{l}\Delta \text { Probability } \\
(\text { Coll | HS })\end{array}$ & $\begin{array}{l}\Delta \text { Probability } \\
\text { (Deg | Coll) }\end{array}$ & $\begin{array}{l}\Delta \text { Probability } \\
\text { (Degree) }\end{array}$ & $\begin{array}{c}\Delta \text { Probability } \\
(\mathrm{HS})\end{array}$ & $\begin{array}{l}\Delta \text { Probability } \\
(\text { Coll } \mid \text { HS })\end{array}$ & $\begin{array}{l}\Delta \text { Probability } \\
\text { (Deg | Coll) }\end{array}$ & $\begin{array}{l}\Delta \text { Probability } \\
\text { (Degree) }\end{array}$ & $\begin{array}{l}\Delta \text { Probability } \\
(\mathrm{HS})\end{array}$ & $\begin{array}{l}\Delta \text { Probability } \\
(\text { Coll | HS })\end{array}$ & $\begin{array}{l}\Delta \text { Probability } \\
\text { (Deg | Coll) }\end{array}$ & $\begin{array}{l}\Delta \text { Probability } \\
\text { (Degree) }\end{array}$ \\
\hline Birth Years 1900-1909 & $7.02 \%$ & $-3.08 \%$ & $0.93 \%$ & $1.09 \%$ & $6.76 \%$ & $-5.32 \%$ & $2.44 \%$ & $1.26 \%$ & $7.27 \%$ & $-1.27 \%$ & $-0.19 \%$ & $0.74 \%$ \\
\hline Birth Years 1910-1919 & $15.44 \%$ & $-5.53 \%$ & $0.33 \%$ & $1.77 \%$ & $15.53 \%$ & $-3.82 \%$ & $-1.61 \%$ & $2.53 \%$ & $15.37 \%$ & $-7.31 \%$ & $1.21 \%$ & $1.13 \%$ \\
\hline Birth Years 1920-1929 & $6.44 \%$ & $2.34 \%$ & $3.64 \%$ & $2.49 \%$ & $5.13 \%$ & $4.42 \%$ & $5.09 \%$ & $3.60 \%$ & $7.85 \%$ & $0.54 \%$ & $1.19 \%$ & $1.34 \%$ \\
\hline Birth Years 1930-1939 & $4.32 \%$ & $2.72 \%$ & $-5.02 \%$ & $0.42 \%$ & $12.08 \%$ & $-4.23 \%$ & $-3.02 \%$ & $0.69 \%$ & $11.50 \%$ & $0.63 \%$ & $4.43 \%$ & $2.72 \%$ \\
\hline Birth Years 1940-1949 & $14.60 \%$ & $10.62 \%$ & $4.21 \%$ & $8.11 \%$ & $10.57 \%$ & $14.34 \%$ & $0.52 \%$ & $8.92 \%$ & $7.33 \%$ & $13.31 \%$ & $3.90 \%$ & $6.75 \%$ \\
\hline Birth Years 1950-1959 & $-3.91 \%$ & $-3.63 \%$ & $5.87 \%$ & $-0.19 \%$ & $-5.06 \%$ & $-9.43 \%$ & $3.97 \%$ & $-4.02 \%$ & $-2.69 \%$ & $2.07 \%$ & $0.35 \%$ & $0.62 \%$ \\
\hline Birth Years 1960-1969 & $2.06 \%$ & $5.94 \%$ & $7.91 \%$ & $6.35 \%$ & $1.34 \%$ & $7.55 \%$ & $4.04 \%$ & $4.93 \%$ & $2.81 \%$ & $4.40 \%$ & $11.62 \%$ & $7.04 \%$ \\
\hline Birth Years 1970-1980 & $-2.94 \%$ & $12.36 \%$ & $-0.60 \%$ & $4.31 \%$ & $-1.05 \%$ & $9.64 \%$ & $-0.60 \%$ & $1.50 \%$ & $-2.87 \%$ & $13.36 \%$ & $3.10 \%$ & $8.57 \%$ \\
\hline B. Decomposition & $\begin{array}{c}\Delta \text { Levels due to } \\
\Delta \mathrm{HS}\end{array}$ & $\begin{array}{c}\Delta \text { Levels due to } \\
\Delta \text { (Coll | HS })\end{array}$ & $\begin{array}{l}\Delta \text { Levels due to } \\
\Delta(\text { Deg | Coll })\end{array}$ & $\begin{array}{l}\Delta \text { Levels due to } \\
\text { Interaction }\end{array}$ & $\begin{array}{c}\Delta \text { Levels due to } \\
\Delta \mathrm{HS}\end{array}$ & $\begin{array}{c}\Delta \text { Levels due to } \\
\Delta(\text { Coll | HS })\end{array}$ & $\begin{array}{l}\Delta \text { Levels due to } \\
\Delta(\text { Deg | Coll })\end{array}$ & $\begin{array}{l}\Delta \text { Levels due to } \\
\text { Interaction }\end{array}$ & $\begin{array}{c}\Delta \text { Levels due to } \\
\Delta \mathrm{HS}\end{array}$ & $\begin{array}{c}\Delta \text { Levels due to } \\
\Delta \text { (Coll | HS })\end{array}$ & $\begin{array}{l}\Delta \text { Levels due to } \\
\Delta(\text { Deg | Coll })\end{array}$ & $\begin{array}{l}\Delta \text { Levels due to } \\
\text { Interaction }\end{array}$ \\
\hline Birth Years 1900-1909 & $1.43 \%$ & $-0.37 \%$ & $0.11 \%$ & $-0.08 \%$ & $1.77 \%$ & $-0.65 \%$ & $0.28 \%$ & $-0.14 \%$ & $1.12 \%$ & $-0.14 \%$ & $-0.02 \%$ & $-0.04 \%$ \\
\hline Birth Years 1910-1919 & $2.96 \%$ & $-0.85 \%$ & $0.05 \%$ & $-0.38 \%$ & $3.78 \%$ & $-0.62 \%$ & $-0.19 \%$ & $-0.40 \%$ & $2.28 \%$ & $-1.03 \%$ & $0.16 \%$ & $-0.42 \%$ \\
\hline Birth Years 1920-1929 & $1.08 \%$ & $0.55 \%$ & $0.67 \%$ & $0.20 \%$ & $1.13 \%$ & $1.10 \%$ & $0.59 \%$ & $0.35 \%$ & $0.95 \%$ & $0.11 \%$ & $0.19 \%$ & $0.05 \%$ \\
\hline Birth Years 1930-1939 & $0.85 \%$ & $0.82 \%$ & $-1.14 \%$ & $-0.11 \%$ & $3.20 \%$ & $-1.36 \%$ & $-0.35 \%$ & $-0.38 \%$ & $1.55 \%$ & $0.17 \%$ & $0.88 \%$ & $0.21 \%$ \\
\hline Birth Years 1940-1949 & $2.66 \%$ & $3.03 \%$ & $1.13 \%$ & $1.29 \%$ & $2.51 \%$ & $5.34 \%$ & $0.06 \%$ & $0.92 \%$ & $1.16 \%$ & $4.59 \%$ & $0.98 \%$ & $0.97 \%$ \\
\hline Birth Years 1950-1959 & $-1.02 \%$ & $-1.43 \%$ & $2.47 \%$ & $-0.21 \%$ & $-1.60 \%$ & $-4.06 \%$ & $0.46 \%$ & $-0.12 \%$ & $-0.66 \%$ & $0.87 \%$ & $0.14 \%$ & $-0.03 \%$ \\
\hline Birth Years 1960-1969 & $0.54 \%$ & $2.31 \%$ & $2.99 \%$ & $0.51 \%$ & $0.35 \%$ & $2.84 \%$ & $0.47 \%$ & $0.30 \%$ & $0.74 \%$ & $1.77 \%$ & $4.67 \%$ & $0.65 \%$ \\
\hline Birth Years 1970-1980 & $-0.99 \%$ & $5.81 \%$ & $-0.25 \%$ & $-0.27 \%$ & $-0.33 \%$ & $4.13 \%$ & $-0.07 \%$ & $-0.10 \%$ & $-1.02 \%$ & $6.87 \%$ & $1.39 \%$ & $0.03 \%$ \\
\hline $\begin{array}{l}\text { C. Totals Pre- and Post } \\
1950 \text { Cohort }\end{array}$ & $\begin{array}{c}\Delta \text { Levels due to } \\
\Delta \text { HS }\end{array}$ & $\begin{array}{c}\Delta \text { Levels due to } \\
\Delta \text { (Coll | HS })\end{array}$ & $\begin{array}{c}\Delta \text { Levels due to } \\
\Delta(\text { Deg | Coll })\end{array}$ & $\begin{array}{l}\Delta \text { Levels due to } \\
\text { Interaction }\end{array}$ & $\begin{array}{c}\Delta \text { Levels due to } \\
\Delta \mathrm{HS}\end{array}$ & $\begin{array}{c}\Delta \text { Levels due to } \\
\Delta(\text { Coll | HS })\end{array}$ & $\begin{array}{l}\Delta \text { Levels due to } \\
\Delta \text { (Deg | Coll })\end{array}$ & $\begin{array}{l}\Delta \text { Levels due to } \\
\text { Interaction }\end{array}$ & $\begin{array}{c}\Delta \text { Levels due to } \\
\Delta \mathrm{HS}\end{array}$ & $\begin{array}{l}\Delta \text { Levels due to } \\
\Delta(\text { Coll } \mid \text { HS })\end{array}$ & $\begin{array}{l}\Delta \text { Levels due to } \\
\Delta \text { (Deg | Coll })\end{array}$ & $\begin{array}{l}\Delta \text { Levels due to } \\
\text { Interaction }\end{array}$ \\
\hline Birth Years 1900-1949 & $8.99 \%$ & $3.17 \%$ & $0.81 \%$ & $0.92 \%$ & $12.38 \%$ & $3.81 \%$ & $0.40 \%$ & $0.35 \%$ & $7.06 \%$ & $3.69 \%$ & $2.19 \%$ & $0.78 \%$ \\
\hline$\%$ of Total $\Delta$ & $64.71 \%$ & $22.86 \%$ & $5.80 \%$ & $6.63 \%$ & $73.10 \%$ & $22.49 \%$ & $2.36 \%$ & $2.06 \%$ & $51.44 \%$ & $26.89 \%$ & $15.98 \%$ & $5.68 \%$ \\
\hline Birth Years 1950-1980 & $-1.47 \%$ & $6.70 \%$ & $5.20 \%$ & $0.03 \%$ & $-1.59 \%$ & $2.90 \%$ & $0.86 \%$ & $0.08 \%$ & $-0.94 \%$ & $9.50 \%$ & $6.20 \%$ & $0.65 \%$ \\
\hline$\%$ of Total $\Delta$ & $-14.05 \%$ & $64.02 \%$ & $49.75 \%$ & $0.28 \%$ & $-70.02 \%$ & $128.26 \%$ & $38.14 \%$ & $3.63 \%$ & $-6.13 \%$ & $61.70 \%$ & $40.23 \%$ & $4.20 \%$ \\
\hline
\end{tabular}

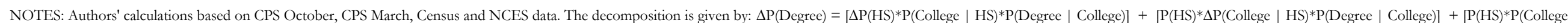

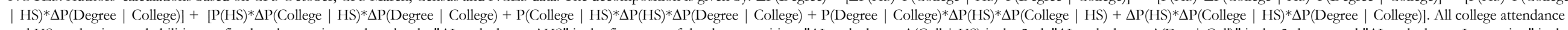

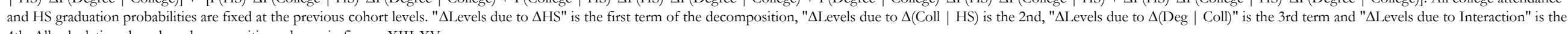
4th. All calculations based on decompositions shown in figures XIII-XV. 
Figure I. High School Status Completion Rate vs. 17-Year Old Graduation Ratio, NCES

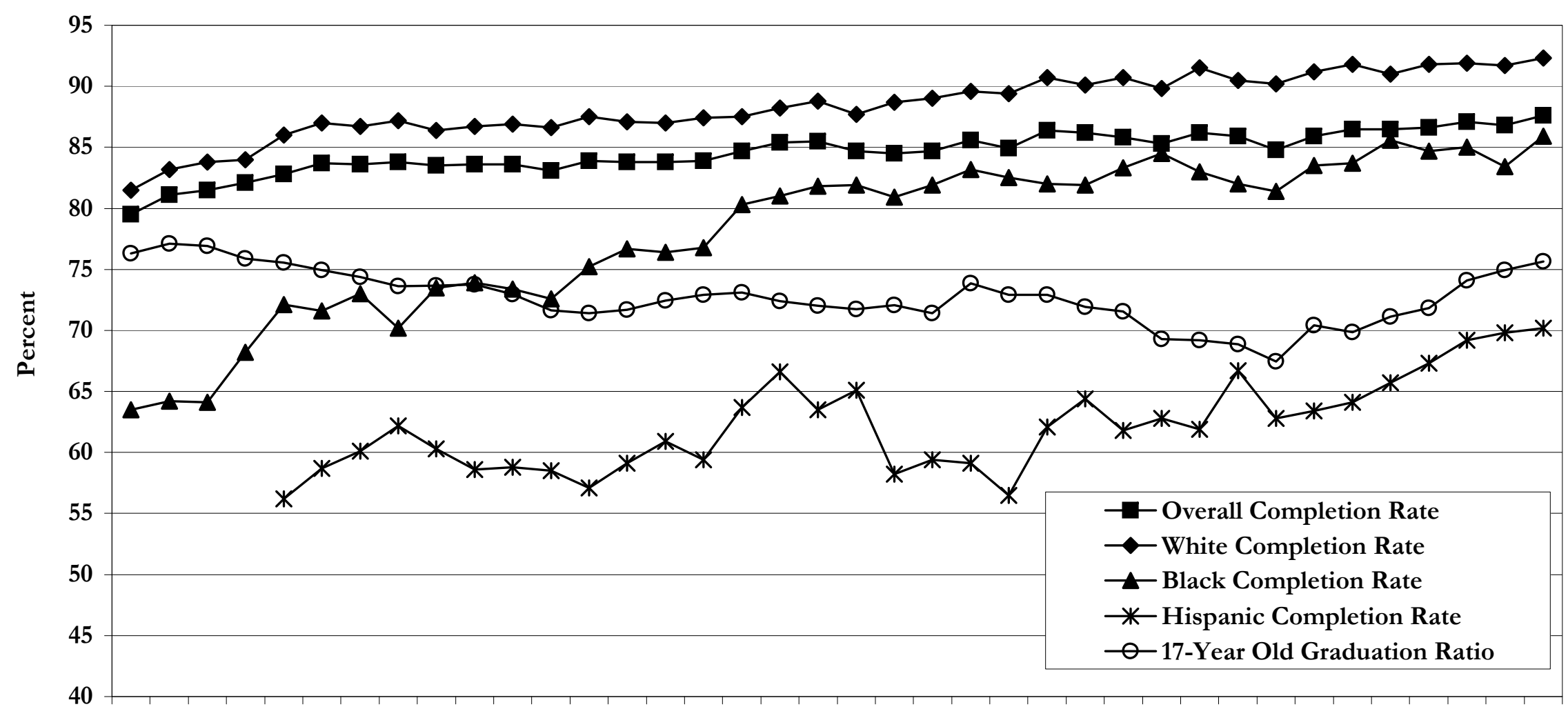

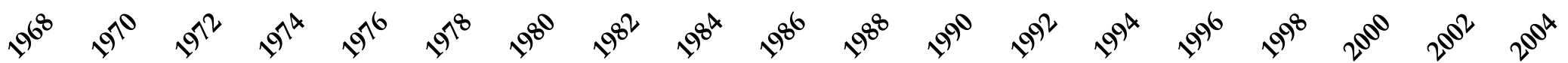

Year

Source: Reproduced from NCES publication "Dropout Rates in the United States: 2005" (Laird et al, June 2007). Rates prior to 1972 are based on authors' calculations using CPS data. The status completion rate is the percentage of 18- through 24-year-olds not enrolled in secondary school who have a high school credential. High school credentials include regular diplomas and alternative credentials such as GED certificates. Hispanic ethnicity is not available before 1972. The 17-year old graduation ratio is from the Digest of Education Statistics. HS graduates for the graduation ratio include both public and private school diplomas and exclude GED recipients and other certificates. October 17-year-old population estimates are obtained from Census Bureau P-20 reports. 
Figure II. Bias in the Estimated Graduation Rate under Various Assumptions, IPUMS 2000

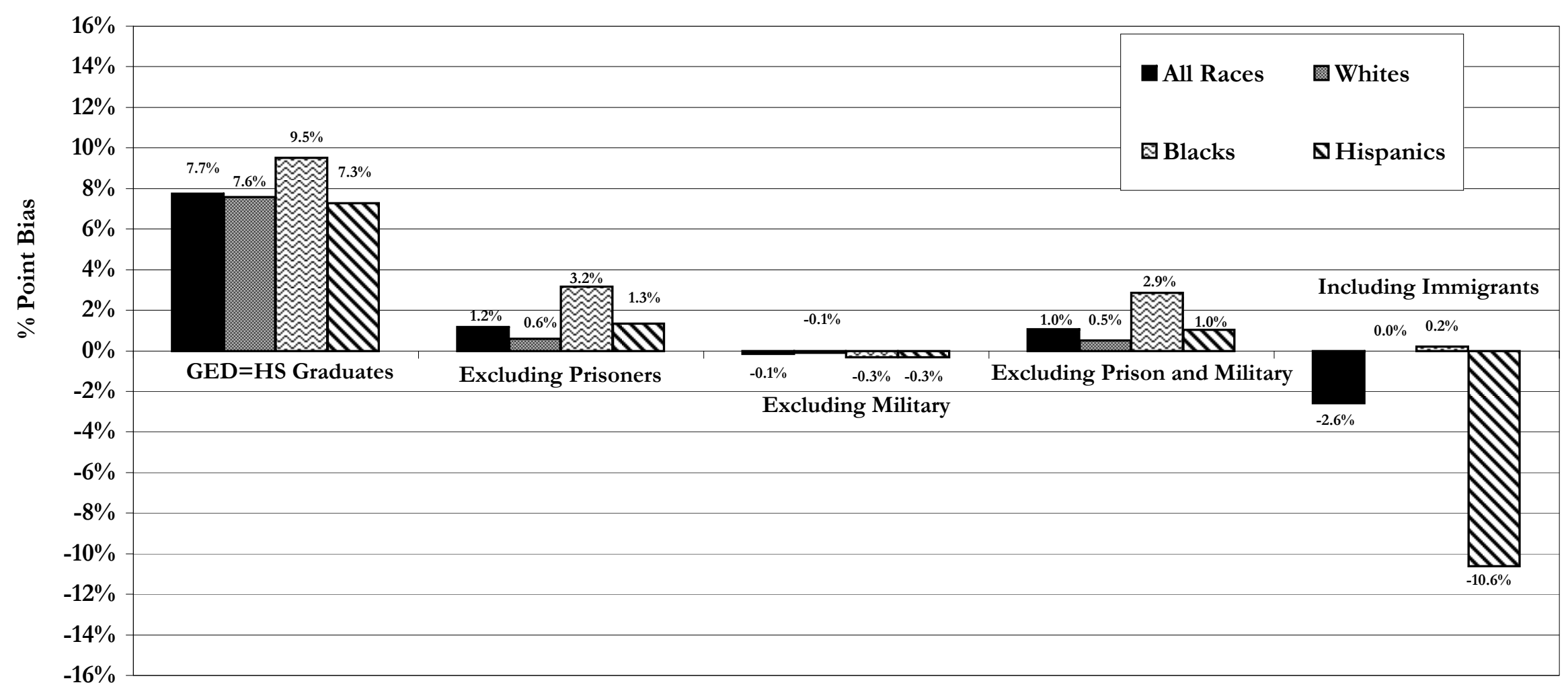

Notes: Authors' calculations based on Census 2000 data. All estimates are weighted and race categories are mutually exclusive. Calculations are for the 20-24 year old population. Total GED recipients are estimated from GED testing service data. The recent immigrant category contains only those who are in the civilian non-institutional population and who emigrated to the U.S. after 1990. Those still enrolled in high school are excluded from calculations. The percentage of GEDs who are recent immigrants is estimated from CPS October data. Estimates of GEDs who are incarcerated or in the military are obtained from BJS and DOD data, respectively. The bias calculations are computed sequentially so that those belonging to multiple groups are only counted once. Immigrants are excluded first, followed by GEDs, prisoners and then the military sample. See the Web Appendix for further details of these calculations. 
Figure III. Bias in the Estimated Male Graduation Rate under Various Assumptions, IPUMS 2000

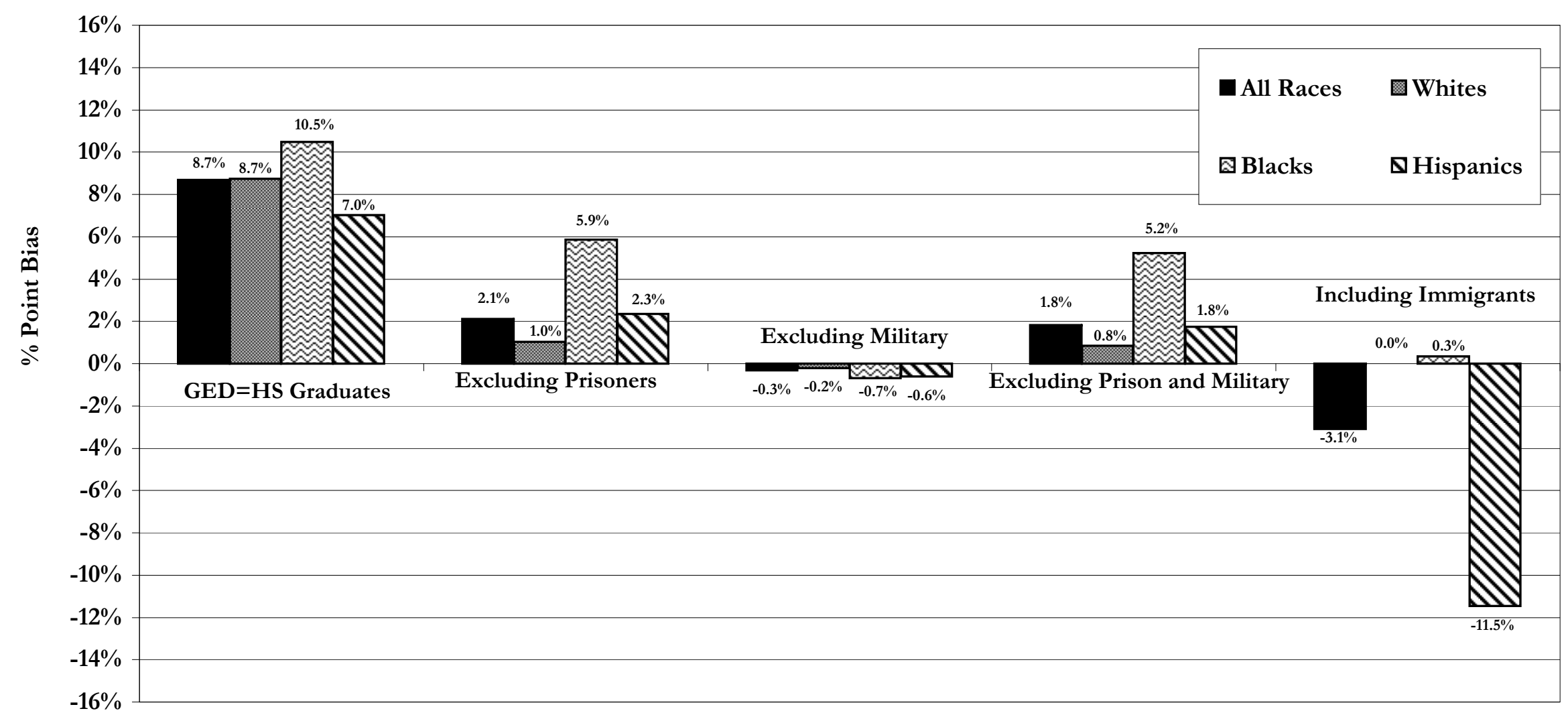

Notes: Authors' calculations based on Census 2000 data. All estimates are weighted and race categories are mutually exclusive. Calculations are for the 20-24 year old population. Total GED recipients are estimated from GED testing service data. The recent immigrant category contains only those who are in the civilian non-institutional population and who emigrated to the U.S. after 1990. Those still enrolled in high school are excluded from calculations. The percentage of GEDs who are recent immigrants is estimated from CPS October data. Estimates of GEDs who are incarcerated or in the military are obtained from BJS and DOD data, respectively. The bias calculations are computed sequentially so that those belonging to multiple groups are only counted once. Immigrants are excluded first, followed by GEDs, prisoners and then the military sample. See the Web Appendix for further details of these calculations. 
Figure IV. Bias in the Estimated Female Graduation Rate under Various Assumptions, IPUMS 2000

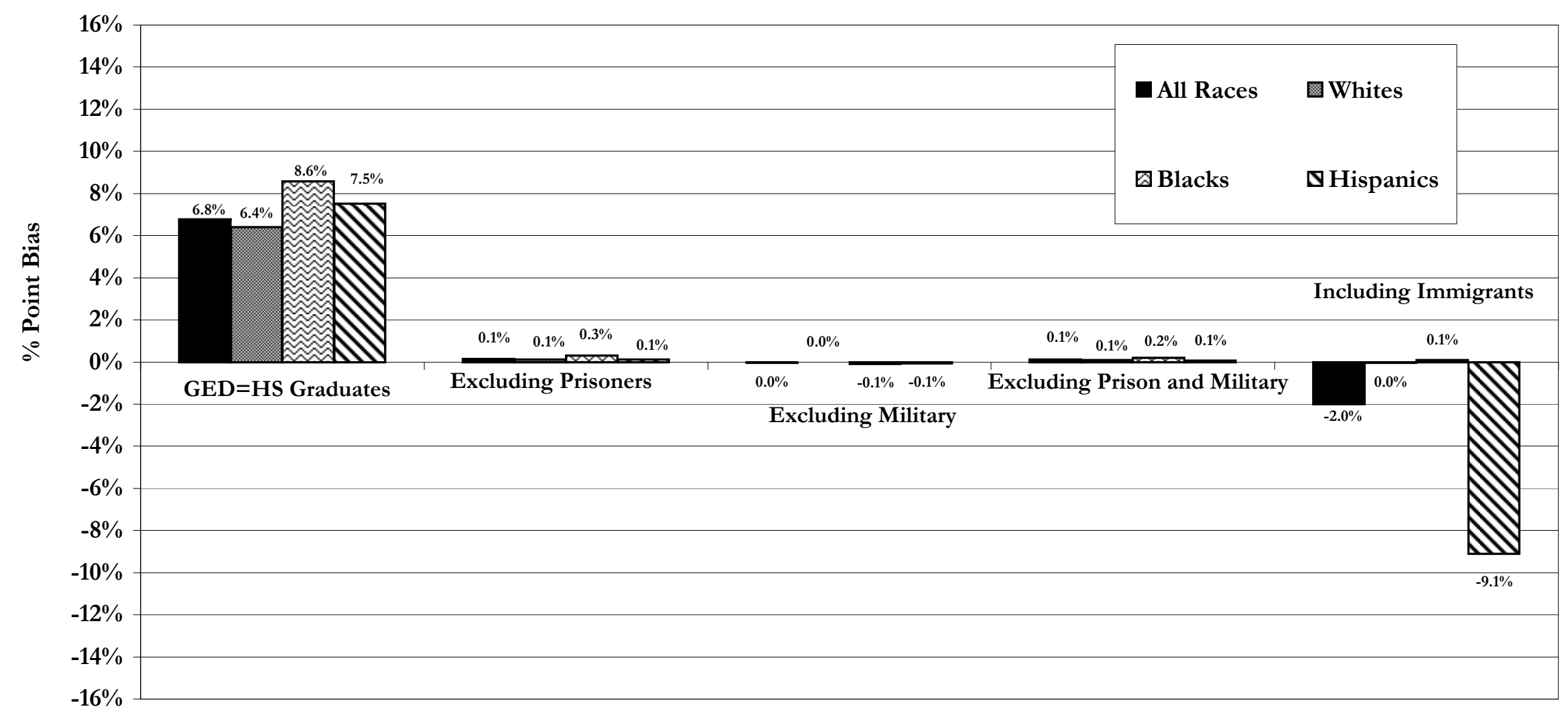

Notes: Authors' calculations based on Census 2000 data. All estimates are weighted and race categories are mutually exclusive. Calculations are for the 20-24 year old population. Total GED recipients are estimated from GED testing service data. The recent immigrant category contains only those who are in the civilian non-institutional population and who emigrated to the U.S. after 1990. Those still enrolled in high school are excluded from calculations. The percentage of GEDs who are recent immigrants is estimated from CPS October data. Estimates of GEDs who are incarcerated or in the military are obtained from BJS and DOD data, respectively. The bias calculations are computed sequentially so that those belonging to multiple groups are only counted once. Immigrants are excluded first, followed by GEDs, prisoners and then the military sample. See the Web Appendix for further details of these calculations. 
Figure V. CPS March vs. Census Comparison of \% of Population Reporting a Given Education Level, Ages 20-24 in 2000

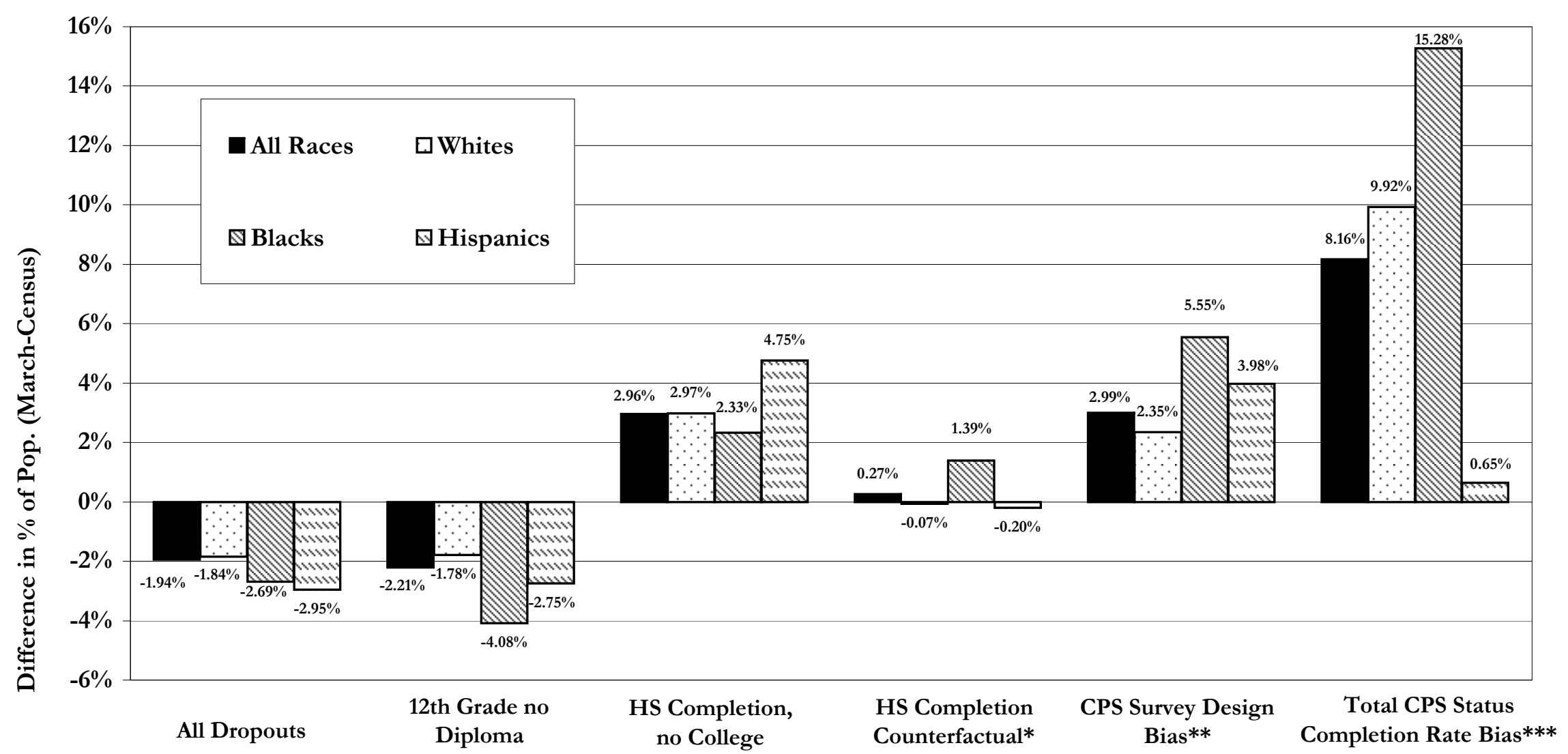

Notes: Authors' calculations based on 2000 CPS March and IPUMS data. All calculations are weighted. High school completers include those who earned a GED. Estimated population totals are 17,974,212 in the Census and 17,982,365 in the CPS March. $\left(^{*}\right)$ The HS counterfactual is the difference between the two surveys in the percentage of the population reporting a high school credential if the \% in the CPS March 12th grade, no diploma, category is set equal to the Census estimate. These additional March dropouts are subtracted from the HS no college category. (**) Computed as the bias from the undercount of dropouts and the exclusion of the institutionalized and military populations in the CPS survey. (***) Total bias from the undercount of dropouts, the exclusion of the institutionalized and military populations, the inclusion of immigrants and counting GEDs as HS graduates in the status completion rate category and are deducted from this category. 
Figure VI. Percentage Change 8th to 9th Grade Public School Enrollment Counts from 1954 to 2005, NCES

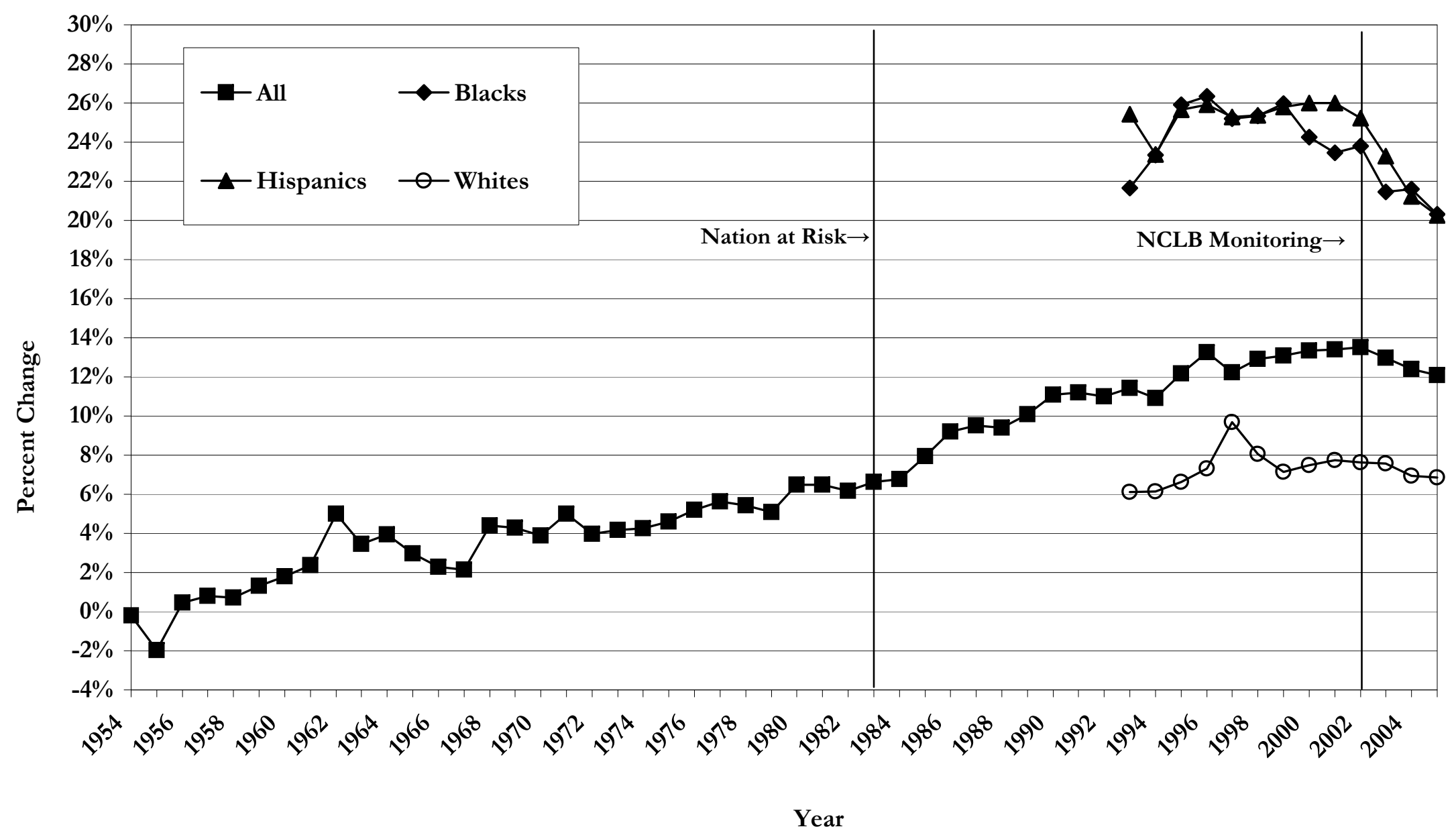

Notes: Authors' calculations based on CCD data obtained from the Digest of Education Statistics (various years). Data by race are only available beginning in 1992. For calculations by race, the following states are dropped in all years due to too many missing values: ID, KY, ND, UT. Enrollment counts by race for some states with missing values were imputed using a linear estimate based on previous and future enrollment counts by race in that state. See data appendix for further details. 
Figure VII. Public High School Graduation Rates by Race Using 8th Grade Estimator: 1960-2005

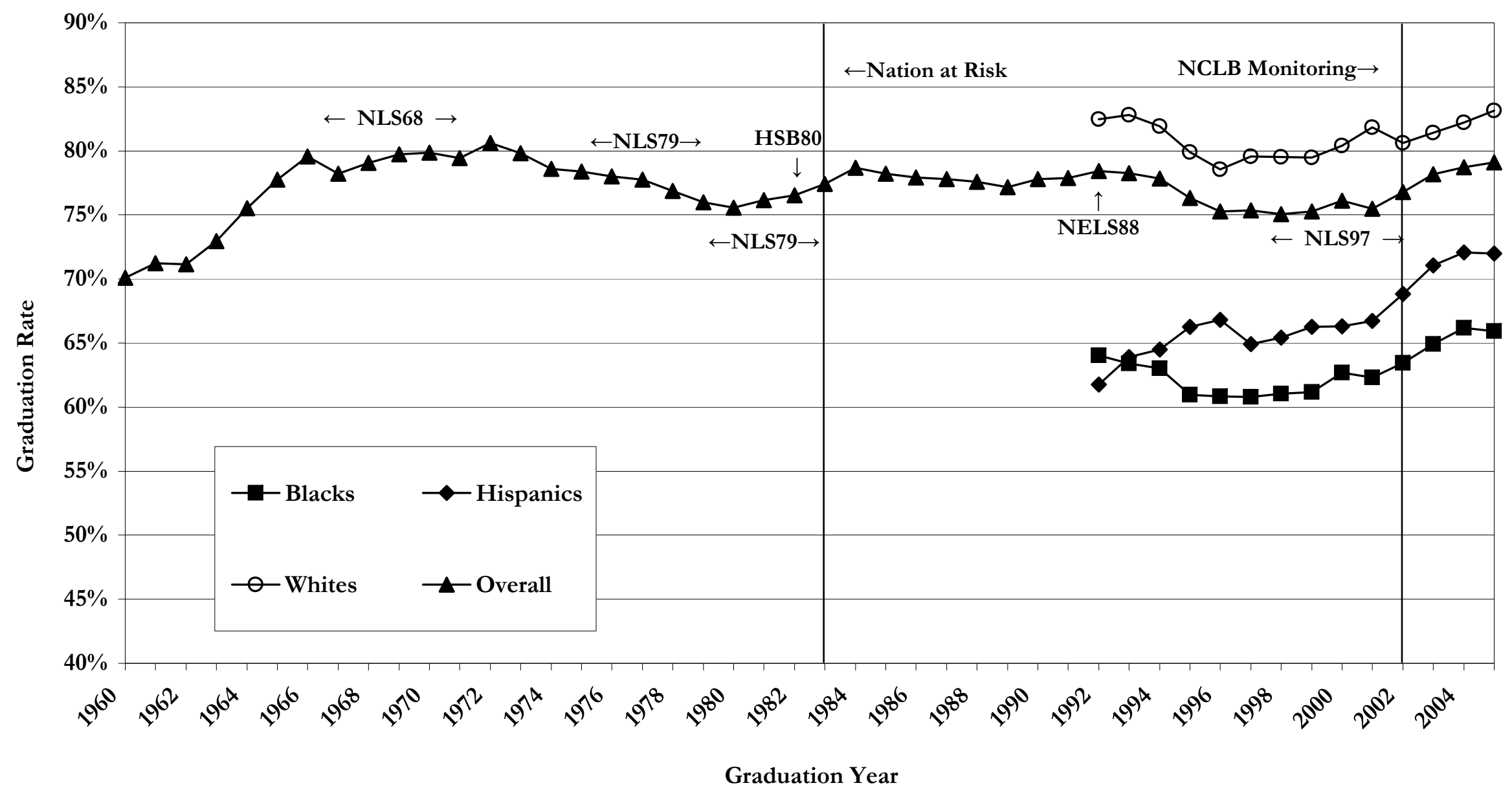

Notes: Authors' calculations based on CCD data obtained from the Digest of Education Statistics (various years). Data by race are only available beginning in 1992. For estimates by race, the following states were excluded in all years due to missing enrollment or diploma counts: ID, KY, ND, NH, SC, UT, VT, WA. Enrollment and diploma counts by race for some states with missing values were imputed using a linear estimate based on previous and future enrollment counts by race in that state. The race distribution of 8th grade enrollments from 1987-1991 are estimated using CPS October data to extend the graduation rates by race to as early as 1992 (the first year diplomas issued by race are available). Ungraded students were distributed across all enrollment totals prior to 1965 . These students are estimated from the 1965 values and subtracted from the totals. See data appendix for further details. 
Figure VIII. Difference between CCD 8th Grade and 9th Grade Estimator of the Public High School Graduation Rate, by Race: 1960-2005

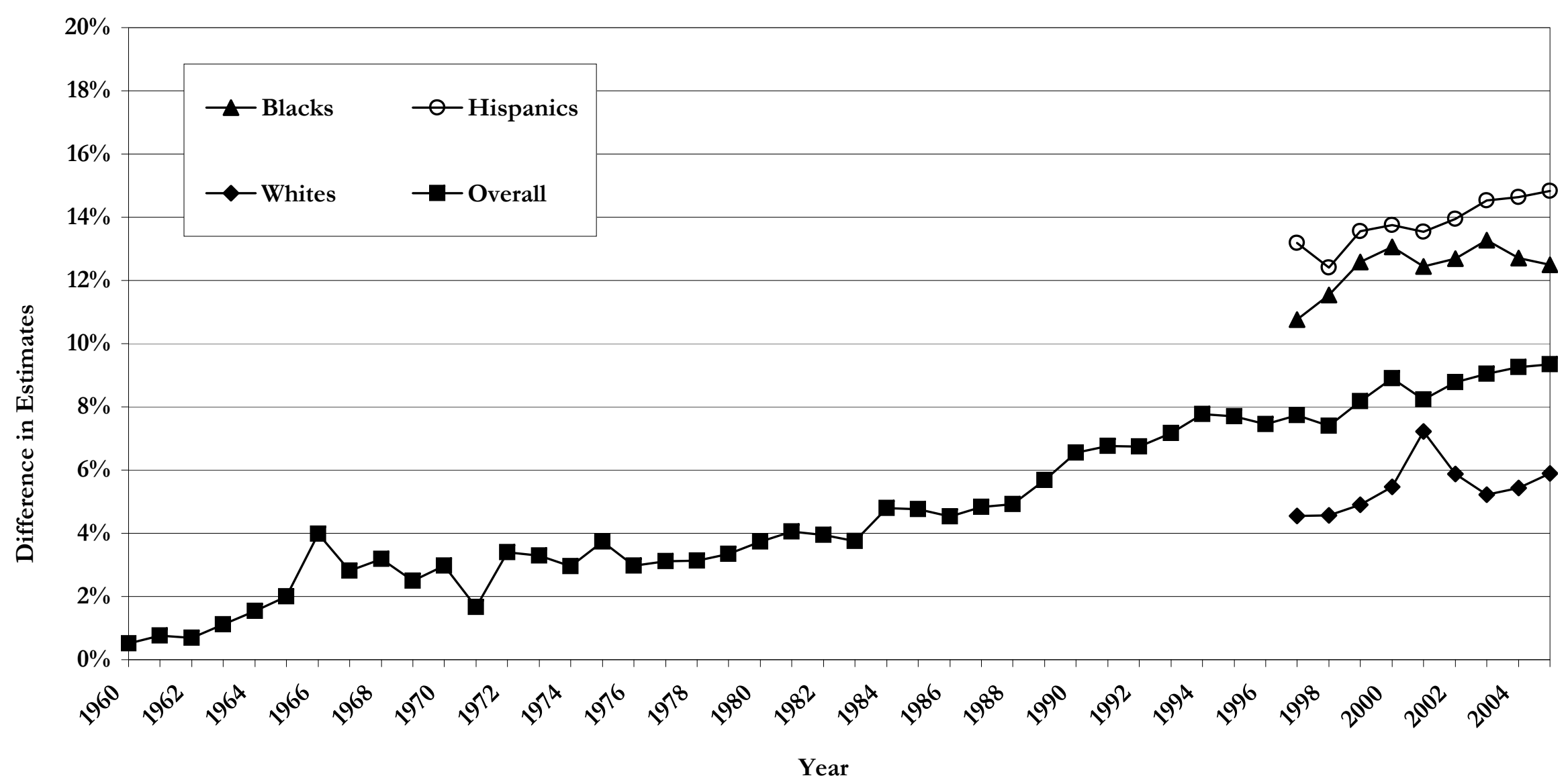

Notes: Authors' calculations based on CCD data obtained from the Digest of Education Statistics (various years). Data by race are only available beginning in 1992. The following states are dropped in all years due to too many missing values: ID, KY, ND, UT. For estimates by race, the following states were excluded in all years: ID, KY, ND, NH, SC, UT, VT, WA due to too many missing values. Enrollment counts by race for some states with missing values were imputed using a linear estimate based on previous and future enrollment counts by race in that state. See data appendix for further details. 
Figure IX. Overall U.S. Graduation Rate by Race, IPUMS 1970-2000

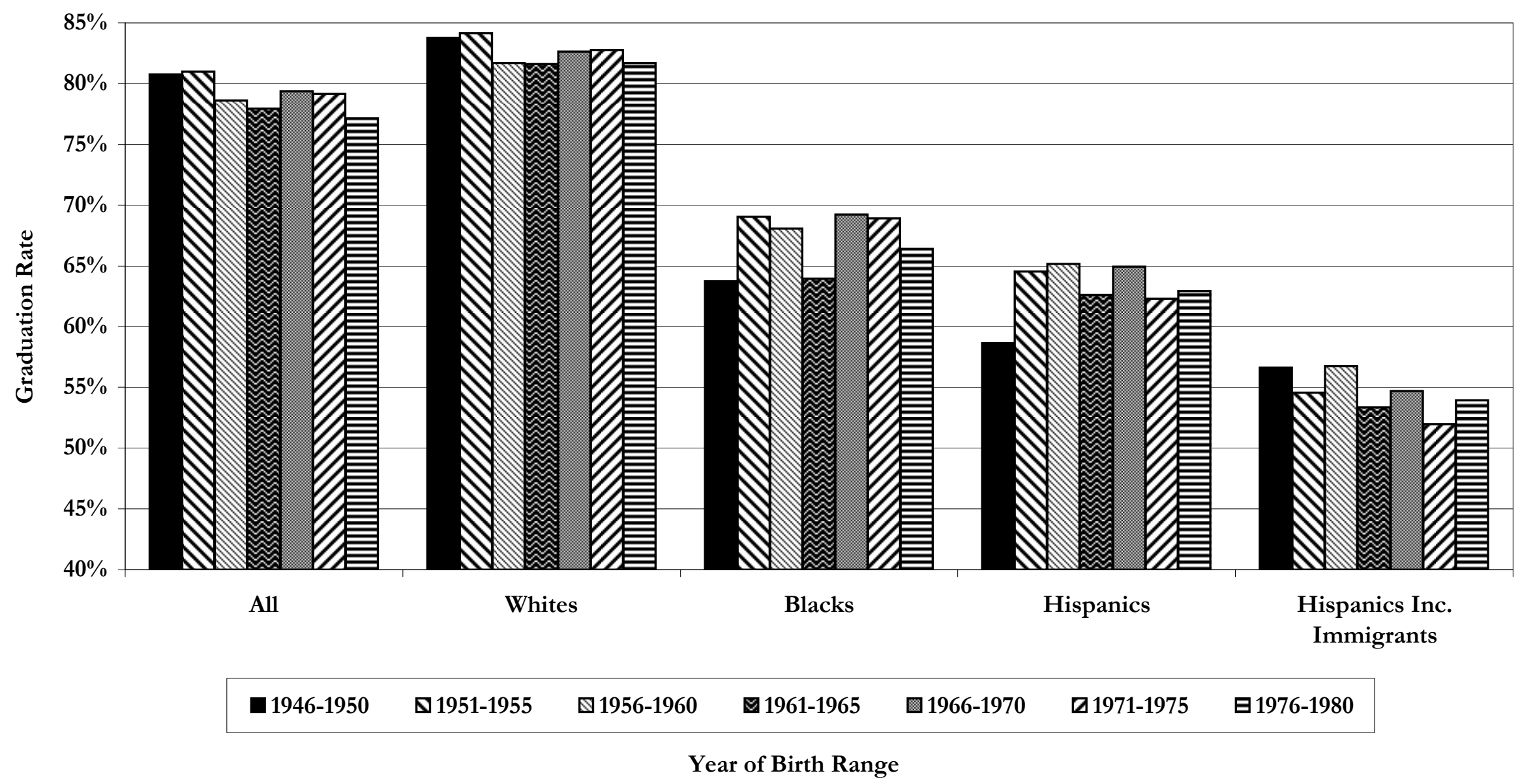

Note: Authors' calculations from Census IPUMS 1970, 1980, 1990 and 2000. Census graduation rates are ages 20-24 or 25-29 depending on cohort and do not include recent immigrants. Recent immigrants are those who entered the U.S. within the last ten years for 20-24 year olds and within the last fifteen years for 25-29 year olds. GED recipients are estimated for each cohort using GEDTS data and are deducted from the Census high school completer totals. Those who report never having enrolled in school are excluded. 
Figure X. Male Graduation Rate Comparisons by Race, IPUMS 1970-2000

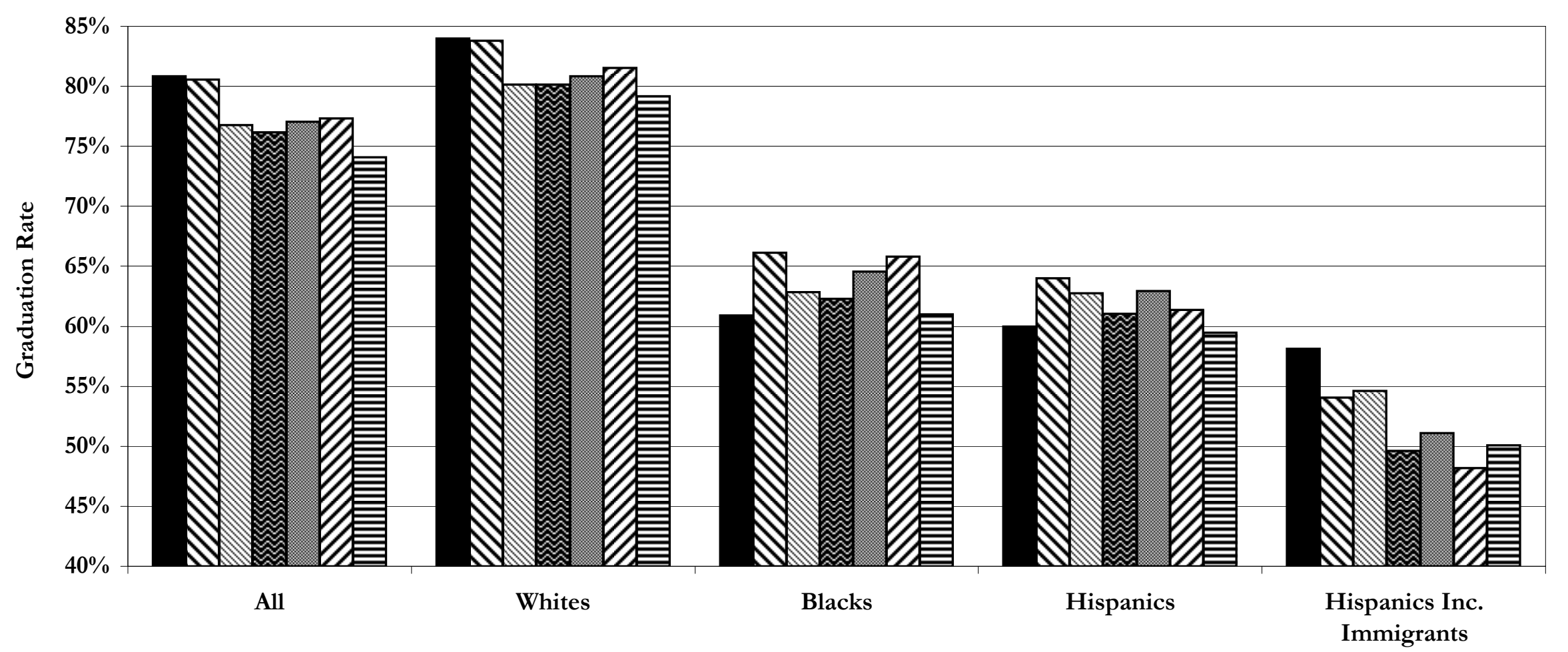

\begin{tabular}{|c|c|c|c|c|c|c|}
\hline -1946-1950 & ธ $1951-1955$ & $\$ 1956-1960$ & ه1961-1965 & 圆1966-1970 & ఐ1971-1975 & 日1976-1980 \\
\hline
\end{tabular}

Notes: Authors' calculations from Census IPUMS 1970, 1980, 1990 and 2000. Census graduation rates are ages 20-24 or 25-29 depending on cohort and do not include recent immigrants. Recent immigrants are those who entered the U.S. within the last ten years for 20-24 year olds and within the last fifteen years for 25-29 year olds. GED recipients are estimated for each cohort using GEDTS data and are deducted from the Census high school completer totals. Those who report never having enrolled in school are excluded. 
Figure XI. Female Graduation Rate Comparisons by Race, IPUMS 1970-2000

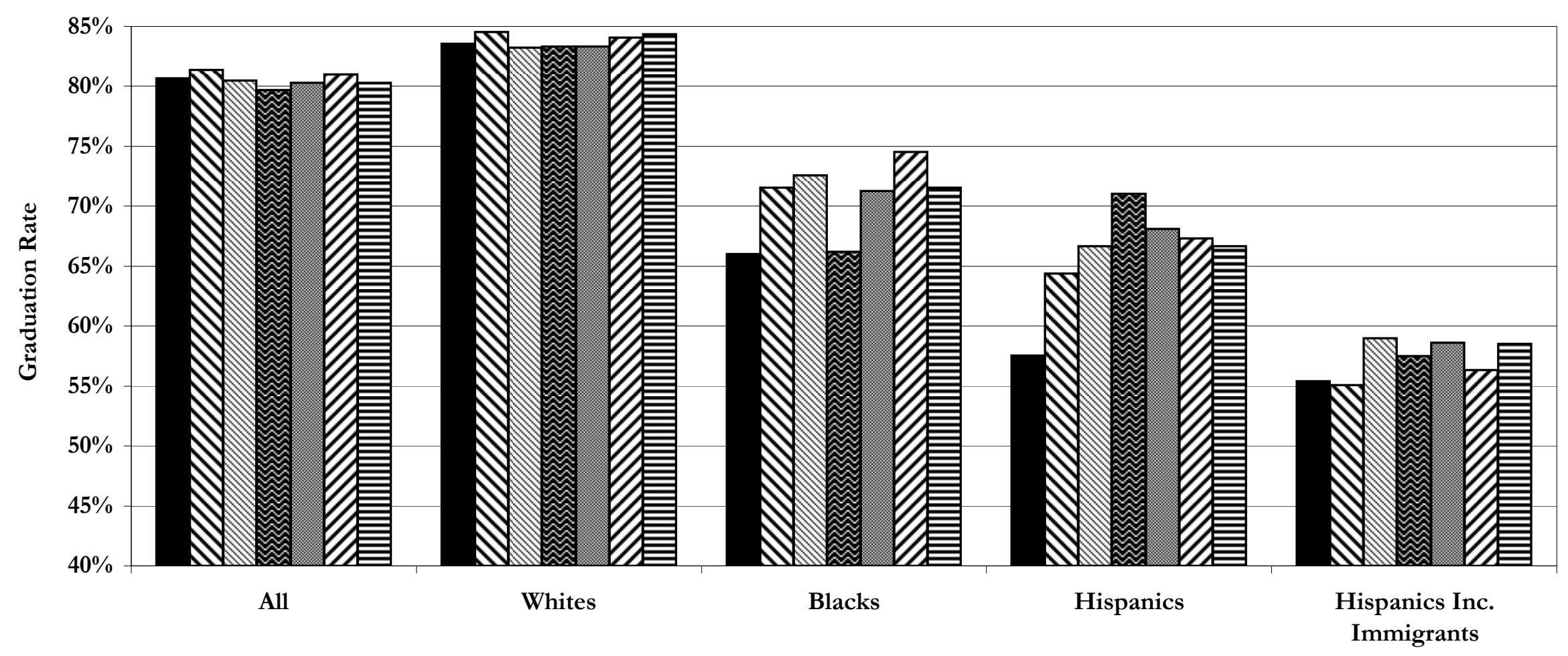
1946-1950
$\mathbf{1 9 5 1 - 1 9 5 5}$
\$ 1956-1960
ล 1961-1965
圆 1966-1970
В 1971-1975
曰1976-1980

\section{Year of Birth Range}

Notes: Authors' calculations from Census IPUMS 1970, 1980, 1990 and 2000. Census graduation rates are ages 20-24 or 25-29 depending on cohort and do not include recent immigrants. Recent immigrants are those who entered the U.S. within the last ten years for 20-24 year olds and within the last fifteen years for 25-29 year olds. GED recipients are estimated for each cohort using GEDTS data and are deducted from the Census high school completer totals. Those who report never having enrolled in school are excluded. 
Figure XII. U.S. Graduation Rate Comparisons Across All Data Sources

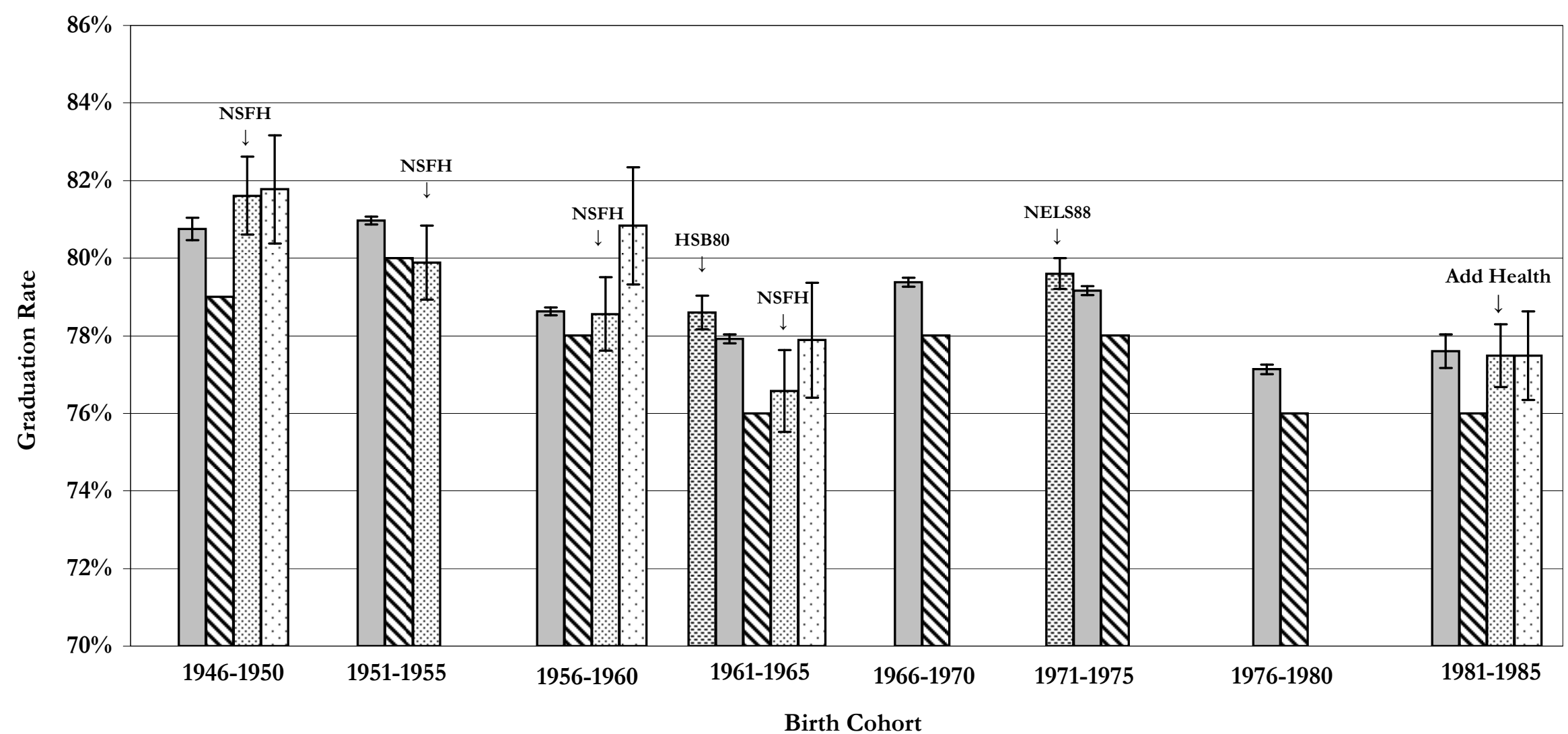

\section{웅 HSB/NELS $\quad \square$ Census $\quad \mathbf{8} 8$ th Grade Estimator $\quad$ OVarious Data Sources (As Labeled) $\square$ NLS}

Notes: Authors' calculations from various data sources. Census graduation rates are ages 20-24 or 25-29 depending on cohort and do not include recent immigrants. The 8th grade estimator is calculated using CCD data. It is assumed that people graduate at age 18. For example, the graduation rate in the year 1968 is for those born in 1950. GED recipients are not counted as high school graduates in all calculations. The NLS data sources are the Young Men and Young women (born 1946-1951), two cohorts of NLSY79 data (those born 1957-1960 and 1961-1964) and the NLSY97 (born 1980-1984). For all survey data, 99\% confidence intervals are shown. CCD data do not allow for standard error calculations. The 1981-1985 "Census" estimates are calculated in the 2004 ACS survey. 
Figure XIII. Educational Attainment Decompositions, Males and Females 1900-1980 Birth Cohorts

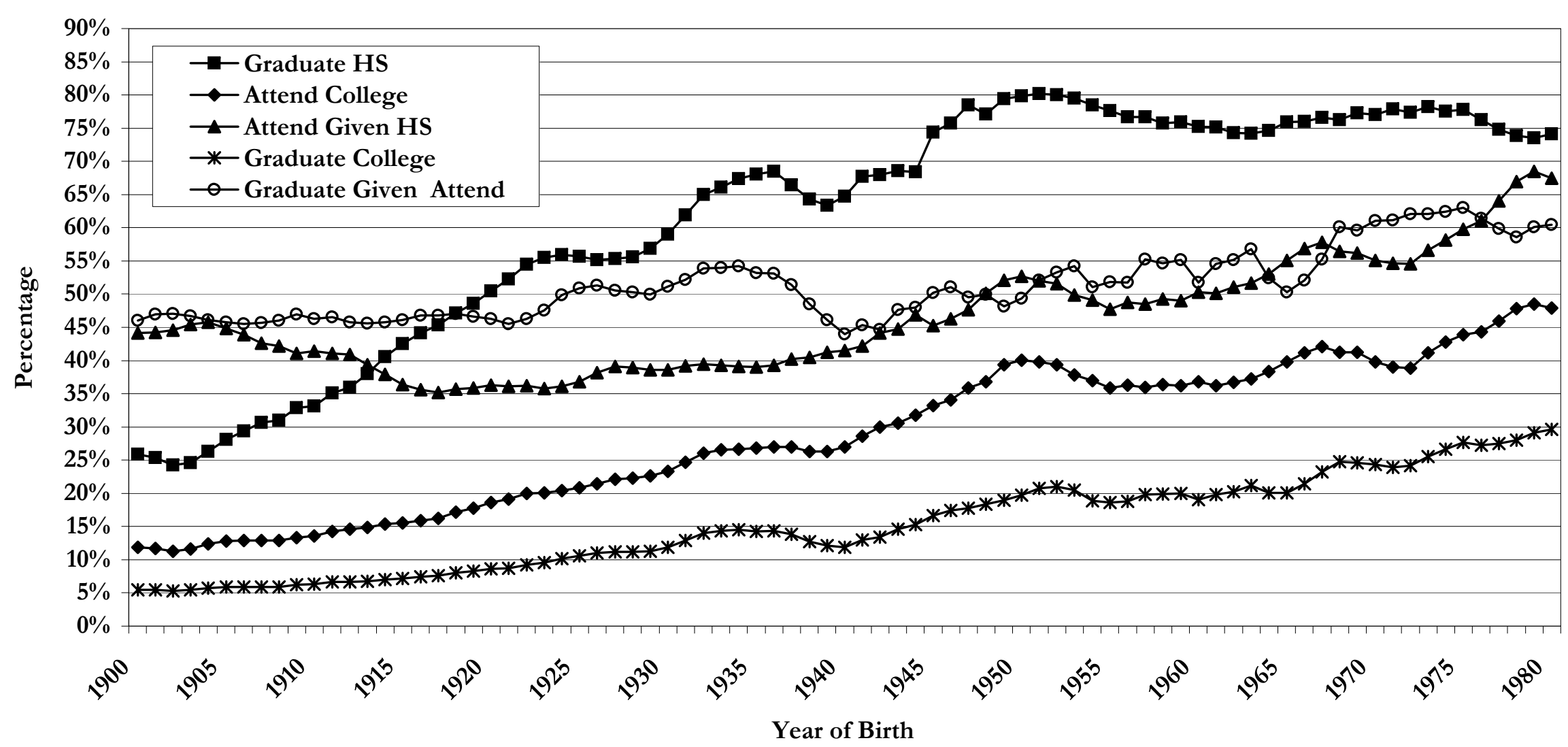

Notes: 3-year moving averages based on CPS October, Census, CPS March and NCES data. HS graduates are those who obtained a regular public or private HS diploma (excluding GEDs) from the NCES. "Graduate HS" is the fraction of 8th grade enrollments for a given cohort who report a regular HS diploma. "Attend Given HS" is the fraction of recent HS graduates who report being enrolled the fall of the year following graduation. "Attend College" is college enrollments of recent HS graduates as a fraction of 18 year old cohort size. College graduates are those who report a BA or higher by age 25. "Graduate Given Attend" is those who obtained a four year degree as a fraction of the college enrollment total for that cohort. Two-year degrees are not included. "Graduate College" is the number of college graduates as a fraction of the 18 year old cohort size. Population estimates are from the Census P-20 reports. HS diplomas issued by sex are estimated from CPS October data after 1982. 
Figure XIV. Educational Attainment Decompositions, Males 1900-1980 Birth Cohorts

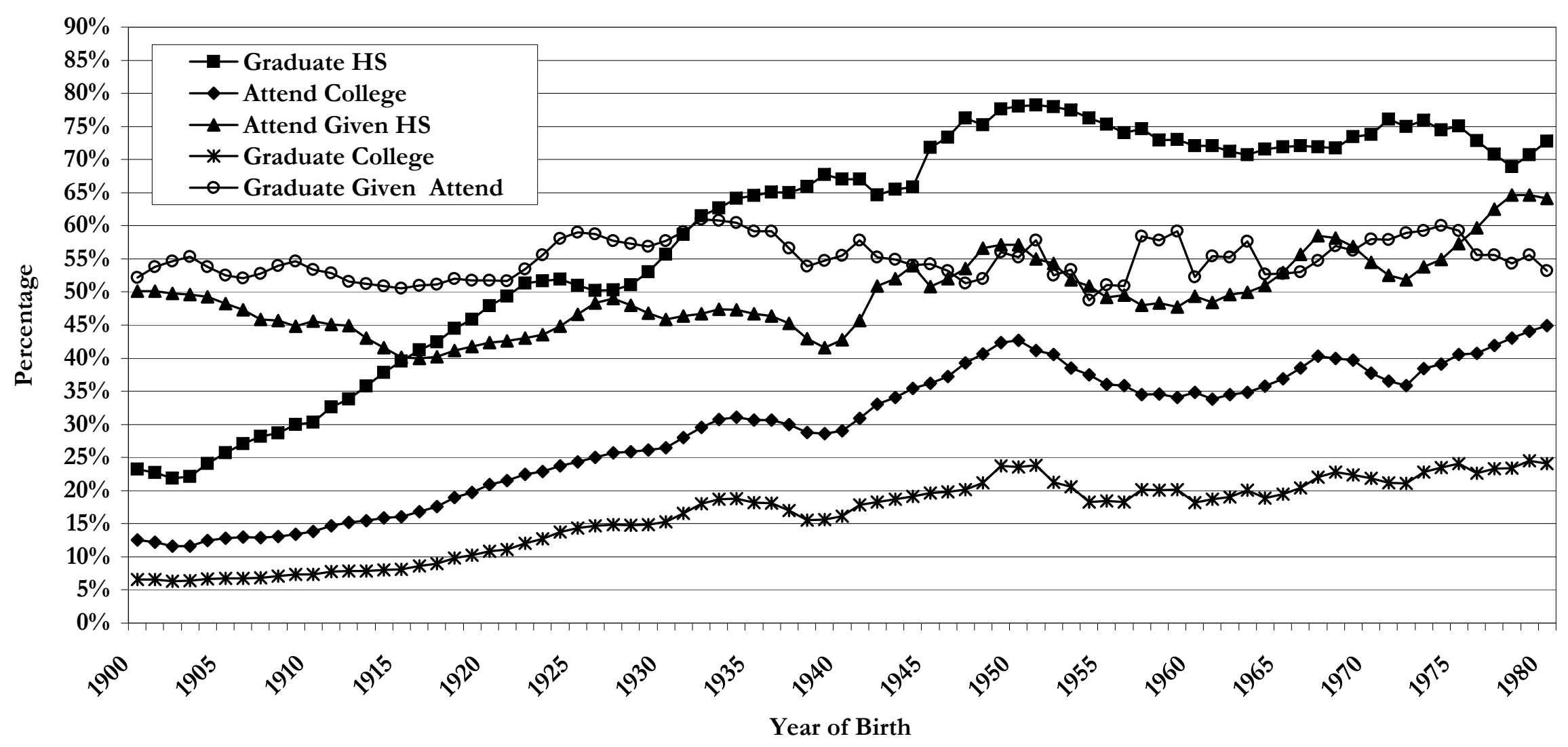

Notes: 3-year moving averages based on CPS October, Census, CPS March and NCES data. HS graduates are those who obtained a regular public or private HS diploma (excluding GEDs) from the NCES. "Graduate HS" is the fraction of 8th grade enrollments for a given cohort who report a regular HS diploma. "Attend Given HS" is the fraction of recent HS graduates who report being enrolled the fall of the year following graduation. "Attend College" is college enrollments of recent HS graduates as a fraction of 18 year old cohort size. College graduates are those who report a BA or higher by age 25. "Graduate Given Attend" is those who obtained a four year degree as a fraction of the college enrollment total for that cohort. Two-year degrees are not included. "Graduate College" is the number of college graduates as a fraction of the 18 year old cohort size. Population estimates are from the Census P-20 reports. HS diplomas issued by sex are estimated from CPS October data after 1982. 
Figure XV. Educational Attainment Decompositions, Females 1900-1980 Birth Cohorts

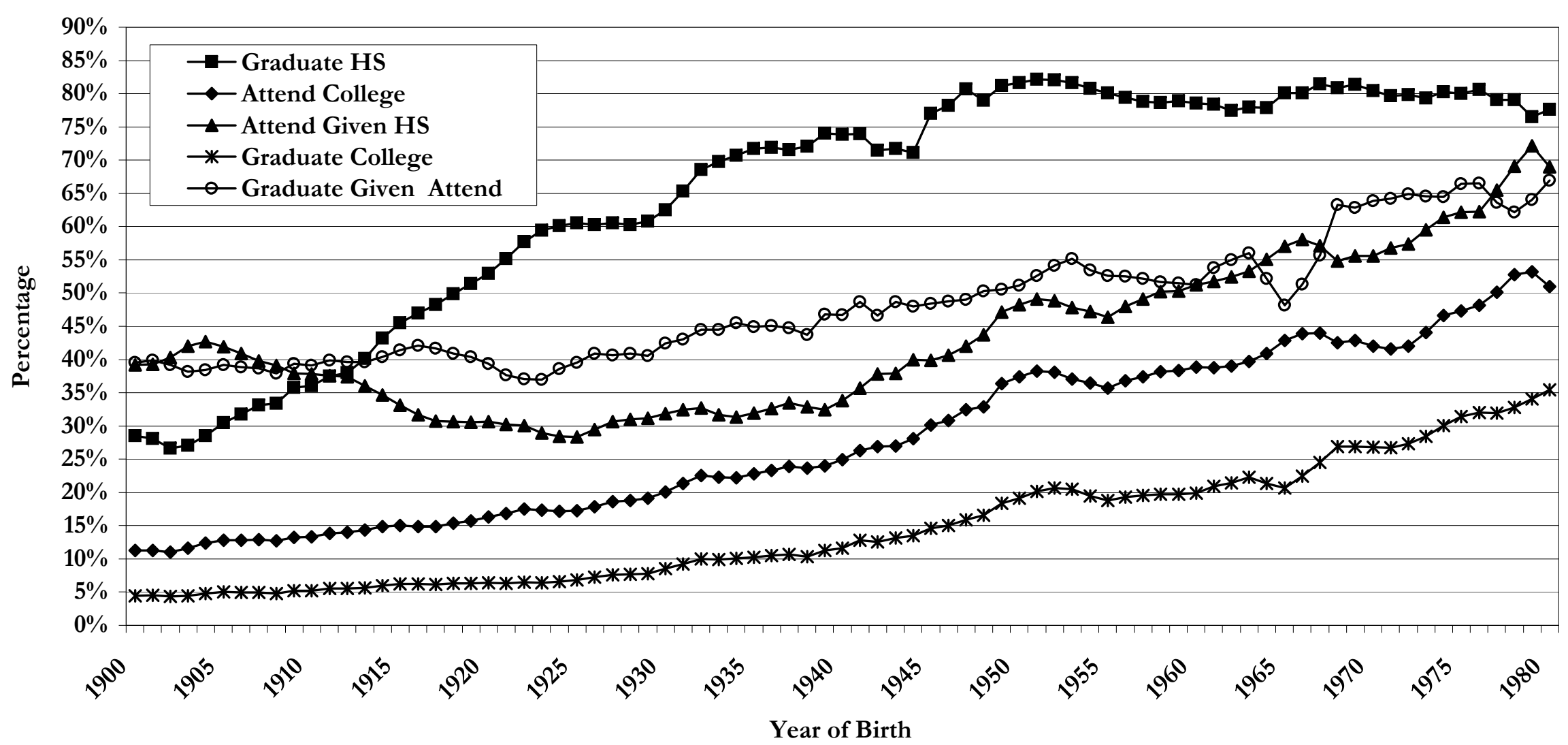

Notes: 3-year moving averages based on CPS October, Census, CPS March and NCES data. HS graduates are those who obtained a regular public or private HS diploma (excluding GEDs) from the NCES. "Graduate HS" is the fraction of 8th grade enrollments for a given cohort who report a regular HS diploma. "Attend Given HS" is the fraction of recent HS graduates who report being enrolled the fall of the year following graduation. "Attend College" is college enrollments of recent HS graduates as a fraction of 18 year old cohort size. College graduates are those who report a BA or higher by age 25. "Graduate Given Attend" is those who obtained a four year degree as a fraction of the college enrollment total for that cohort. Two-year degrees are not included. "Graduate College" is the number of college graduates as a fraction of the 18 year old cohort size. Population estimates are from the Census P-20 reports. HS diplomas issued by sex are estimated from CPS October data after 1982. 